\title{
إستخدام الأجـهـزة الإلكترونية وأثرها على سلوك الأطـفال من وجهة نظر الوالدين \\ (دراسة وصفية على عينة من آباء وأمهات طلاب الصفوف العليا للمرحلة الابتدائية بمحافظة جدة)
}

Use of Electronic Equipment and Their Impact on Children Behavior "Point of view parental"

(Descriptive study on a sample of children and their mothers in primary school upper classes in Jeddah)

\section{إعداد الباحث/ حمدان بن عبده بن عبد الله الثهري}

ماجستير التوجيه و الإصلاح الأسري، قسم الاجتماع و الخدمة الاجتماعية، كلية الآداب و العلوم الإنسانية، جامعة الملك عبد العزيز،

$$
\text { المملكة العربية السعودية }
$$

Email: hamdan4d@gmail.com

المستخلص:

هدفت الدر اسة إلى معرفة العلاقة بين مستوى التحصيل الدر اسي للطفل واستخدام الأجهزة الإلكترونيـة كما اهتمت بكثَف

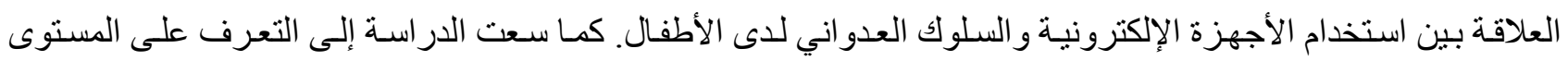
التعليمي و الاقتصادي للأسرة وعلاقتها بامتلاك الأطفال للأجهزة الإلكترونية. كما هدفت لمعرفة العلاقة بين استخدام الأجهزة الإلكترونية و الانعز ال و الانطو اء لاى الأطفال. و التعرف على العلاقة بين استخدام الأجهزة الإلكترونية والصحة العامة للطفل. تم في هذه الدراسة استخدام المنهج الوصفي التحليلي، الذي يعبّر عن الحالة المدروسة نعبيرًا كميًا وكيفيًا، حيث يمكنتاوصف وتتخيص موضوع البحث وتحليل بعض جو انبه، كما أشنار عبيدات وزملائه (2004)، بأنه عبارة عن أسلوب يعتمد در اسـة الو اقع أو الظاهرة كما توجد في الو اقع، وتسهم بوصفها وصفاً دقيقاً، ويعبر عنها تعبير أ كيفياً أو كمباً. وقد بلغت عينـة الدراسـة (411) مـن أبـاء و أمهات حيث بلـغ عدد الابـاء (294) و الأمهات (117). تمت معالجـة بيانـات الدر اسـة باستخدام الأسـاليب الإحصائية) (Spss) المناسبة لطبيعة هذه الدر اسة وذلك عن طريق المتوسطات الحسـابية و الانحر افات المعياريـة. كما أوصت الدر اسة إلى ما يلي: مشاركة الاطفال في وضع قو اعد خاصة حول الاستخدام السليم والآمن للجهاز مثل تحديد الوقت و المكان و المدة المسموح بها. مساعد الاطفال على تعلم كيفية الحفاظ على خصوصية المعلومات الثخصية خاصةً من الغرباء، فبعض الأشخاص ليسو اكما يدعون. تذكير الأطفال بـأن ما يحدث عبر الإنترنت ييقى على الإنترنت ومن الصعب حذفه كالرسائل

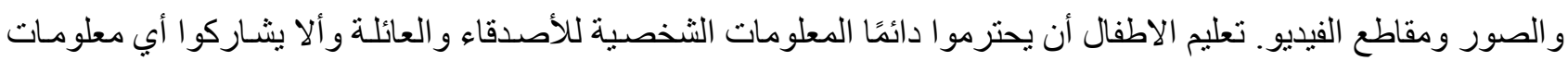
عن الآخرين قد تسبب لهم أي إحر اج أو أذى. عدم ترك الاطفال يتنـاولون طعامهم أثناء ممارسـاتهم الالعـاب الالكترونيـة عبر

الكلمات المفتاحية: الأجهزة الإلكترونية، سلوك الأطفال، وجهة نظر الوالدين، طلاب الصفوف العليا، المرحلة الابتدائية، بمحافظة جدة 


\section{Use of Electronic Equipment and Their Impact on Children Behavior "Point of view parental" (Descriptive study on a sample of children and their mothers in primary school upper classes in Jeddah)}

\section{Abstract:}

The study aimed to find out the relationship between the child's academic achievement level and the use of electronic devices. It also focused on revealing the relationship between the use of electronic devices and aggressive behavior among children. The study also sought to identify the educational and economic level of the family and its relationship to children's ownership of electronic devices. It also aimed to know the relationship between the use of electronic devices and isolation and introversion in children. And to identify the relationship between the use of electronic devices and the general health of the child. In this study, the descriptive analytical method was used, which expresses the studied case quantitatively and qualitatively, where we can describe and diagnose the subject of research and analyze some of its aspects, as indicated by Obeidat and his colleagues (2004), that it is a method that depends on the study of reality or phenomenon as it exists in reality, It contributes as an accurate description, and is expressed qualitatively or quantitatively. The study sample amounted to (411) fathers and mothers, where the number of fathers was (294) and mothers (117). The study data were processed using statistical methods (Spss) appropriate to the nature of this study, by means of arithmetic means and standard deviations. The study also recommended the following: Children's participation in setting special rules about the proper and safe use of the device, such as determining the time, place and duration allowed. Helping kids learn how to keep personal information private from strangers, some people are not what they claim. Remind children that what happens online stays online and is difficult to delete such as messages, photos and videos. Teach children to always respect the personal information of friends and family and not to share any information about others that could cause them embarrassment or harm. Not letting children eat their food while they are playing electronic games through the devices.

Keywords: Electronic devices, Children's behavior, Parents' point of view, Upper grade students, Primary school, Jeddah governorate. 
يمر العالم بأسره بمجمو عة من التغير ات المهمة والمتسار عة على المستوى التقني و الرقمي، كـان من أبرزهـا التطور

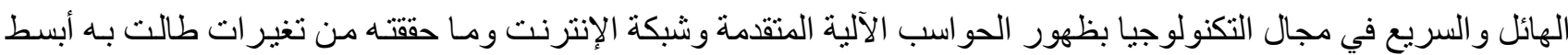
مناحي حياتتا، الا أنَّ ظهور الأجهزة الإلكترونية الحديثة من هو اتف ذكية وأجهزة لوحية وكفية وألعاب الكترونية نـال النصيب

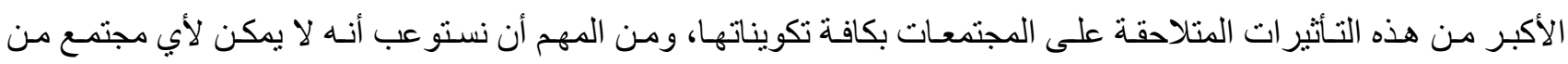

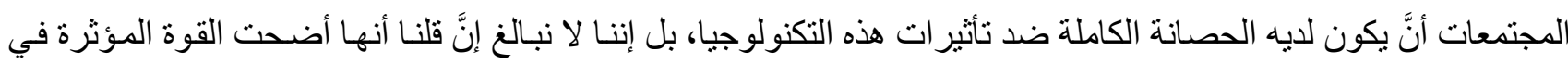
النسيج الاجتماعي و النظام العالمي بسبب تشبعها و انتشار ها اللامحدود .

إنَّ تربية الأبناء على القيم و المبادئ الإسلامية هي من الركائز الأساسية للأسرة وتعد هاجساً يؤرقها منذ السنوات

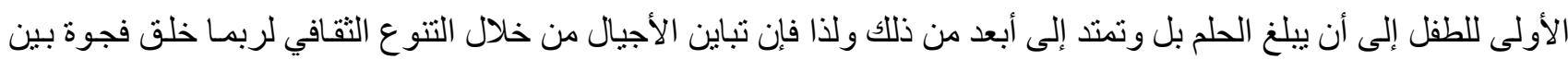
الأبناء و اسر هم بحكم أن الأسرة بها أجيال مختلفة جيل رقمي و هم جيل الأبناء وجيل المهاجر الرقمي ونقصد بالجيل الرقمي هم

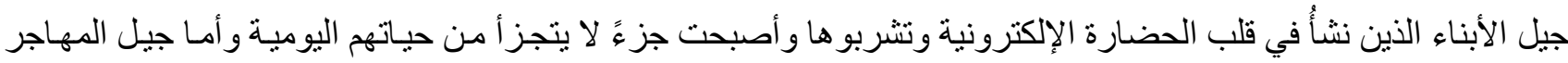
الرقمي فهم جيل الآباء الذين يحاولون جاهدين جار اة ومواكبة الانفجار المعلوماتي و التقني فهم مهاجرون إلى ذلك العالم لعلهم أن يعو اويفهموا طريقة التعامل مع تللك الأجهزة الحديثة وبكل تأكيد التباين التقني و المعلوماتي الإلكتروني بين الجيلين مختلف تماماً وذلك الاختلاف سيحدث فجوة بين الآباء واطفالهم بسبب سر عة ودقت التغييرات التي تطر أ على تللك الأجهزة الإلكترونية

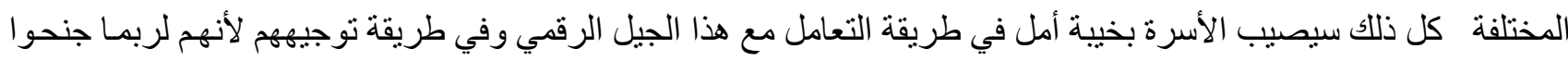

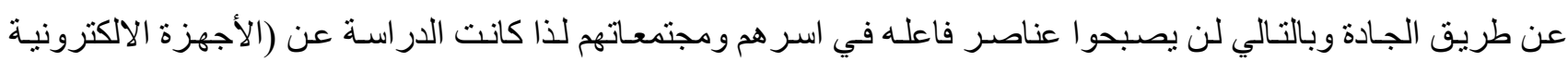

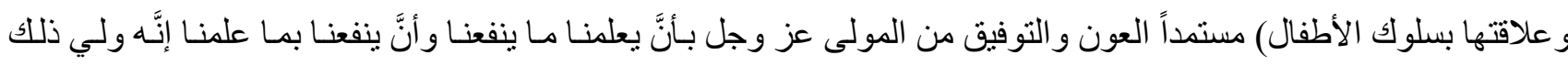

نتيجة للتورة الصناعية والتكنولوجية الهائلة التي غزت العالم في الآونة الأخيرة ظهرت مجموعة كبيرة من الأجهزة الإلكترونية التي طوَّر عليها الإنسان وماز ال بطور حتى تلبي احتياجاته الكثيرة والمختلفة بكل سهولة ويسر وبأقل وقت وجهد

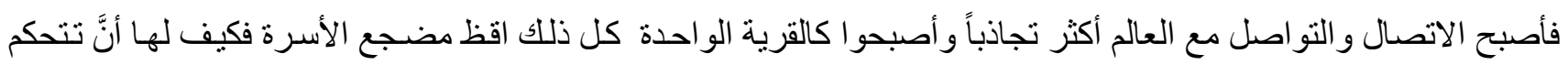
وتسيطر على استخدام أطفالها للأجزةة الالكترونية وماهي نوعية البرامج التي يشـاهدونهاو الألعاب التي يمارسونها والأجهزة التي يمتلكونها إذا مـا أخذنا بعين الاعتبار بـأن الانفجـار المعلومـاتي والتقني حدث بطرق متسـار عة ومتجدده فأصبحت عجلة

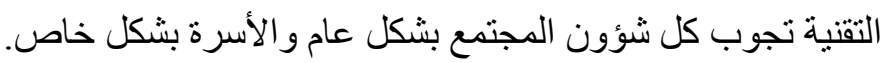

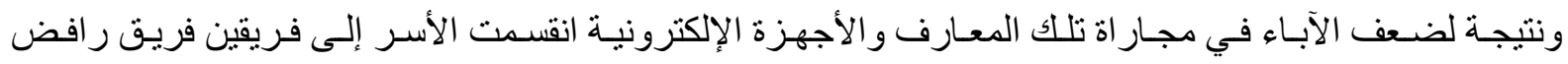
ومحارب لها ويرى أنها تخل بالتربية وفريق آخر تقبل و انسجم وتعـايش معها واستطاع أن ينأقلم مع تلك التحو لات التقنية 
و المعلوماتية وبين هذا وذاك يمكن القول بأن مشكلة الدر اسة تتحدد في الإجابة على تساؤل رئيس ما علاقة الأجهزة الالكترونيـة بسلوك الأطفال وما المر اد بالأجهزة الإلكترونية وما المقصود بسلوك الأطفال و التعرف على اهم المؤثرات السلبية.

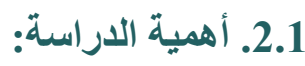

\section{أولاً: الأهمية النظرية للاراسة:}

تمثل الدر اسة واحدة من الدر اسات التي تسهم في إثر اء البحوث التي تقع ضمن تخصص علم الاجتمـاع الأسري و التربوي فيستفيد منها على حدٍ سواء الآباء و المربون في الميدان التربوي.

يؤمل أن تسهم الدراسة في التعرف على اهم التحديات التي تواجه الطفل عند استخدام الأجهزة الإلكترونية. توضيح بعض الأفكار الثائعة حول علاقة الأجزة الالكترونية بسلوك الأطفال.

\section{ثانيا: الأهمية التطبيقية للار اسة:}

نأمل أن تسهم الدر اسة إن شاء الله في تنمية مهار ات الآباء و المربون في كيفية التعامل مع أبنائهم في ظل الانفتاح التقني و التكنولوجي.

تُتيح الدر اسة للمختصين و المهتمين بجانب الطفولة بوضع بر امج علاجية تضبط استخدام الأجهزة الإلكترونية للأطفال. تظافر جهود الجهات ذات العلاقة في تبصير المجتمع المدني بأهمية ذلك والمخاطر المحتملة.

1. التعرف على العلاقة بين مستوى التحصيل الدر اسي للطفل واستخدام الأجهزة الإلكترونية. 2. الكثف عن العلاقة بين استخدام الأجهزة الإلكترونية و السلوك العدو اني لدى الأطفال. 3. التعرف على المستوى التعليمي و الاقتصادي للأسرة و علاقتها بامتلاك الأطفال للأجهزة الإلكترونية. 4. الكثف عن العلاقة بين استخدام الأجزة الإلكترونية و الانعز ال والانطو اء لدى الأطفال.

5. التعرف على العلاقة بين استخدام الأجهزة الإلكترونية و الصحة العامة للطفل. 6. الكثف عن العلاقة بين استخدام الأجهزة الإلكترونية وفرط الحركة لدى الأطفال.

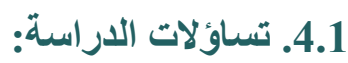

1. هل توجد علاقة بين التحصيل الدر اسي و عدد ساعات استخدام الأطفال للأجهزة الإلكترونية. 2. هل توجد علاقة بين الأجهزة الالكترونية و السلوك العدو اني لدى الأطفال. 
3. هل توجد علاقة بين المستوى التعليمي والاقتصادي للأسرة وامتلاك الأطفال للأجهزة الإلكترونية. 4. هل توجد علاقة بين الأجهزة الإلكترونية والانطواء و الانعزال عند الأطفال. 5. هل توجد علاقة بين الأجهزة الإلكترونية والناحية الصحية لاى الأطفال. 6. هل توجد علاقة بين الأجهزة الإلكترونية وفرط الحركة لدى الأطفال.

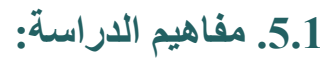

\section{أولاً: مفهوم الأجهزة الإكترونية:}

التعريف النظري: تدخل ضمن تكنولوجيا المعلومات والاتصال والتي تعرف على أنها جميع التكنولوجيات الحديثة التي تستعمل في الاتصـال بين الأشخاص مثل تجهيز ات الإعلام الآلي و البرمجيات و الحو اسبب وتجهيز ات المكاتب و الثبكات و الهو اتف المحمولة و الثابتة و غير هـا، كمـا أنها ذلك المزيج من تقنية معالجة المعلومـات وحفظها وتقنية ونقل وتوزيع المعلومـات، وقد

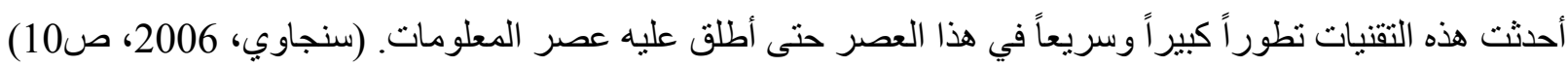
ويعرفه الباحث اجر ائياً: بأنها مجمو عة من الأجهزة التي تخضع لتقنية الكترونيـة ويمكن للإنسـان استخدامها في حياته اليومية وتطويعها لاحتياجاته الأساسية كالتلفاز وأجهزة الكمبيوتر والهواتف النقالة والألعاب الإلكترونية.

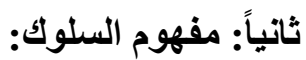
التعريف النظري: يشمل الأفعال الحركية التي تصدر عن الكائن البشري والأفعال اللغويـة التي يتفوه بها كمـا يشـل المشـاعر و الوجدانيات و الانفعالات الباطنة. (القومي، 1984) كما يعرف بانه أي نشاط يصدر عن الإنسـان سواءً كان أفعال يمكن ملاحظتها وقياسـها كالنشـاطات الفسيولوجية والحركيـة أو نشاطات تتم على نحو غير ملحوظ كالتفكير والتذكر و غير ها. (الفسفوسي، 2011) ويُعرف السلوك الباحث اجر ائياً: بأنه ردود أفعال فئة عمرية من الأطفال عند استخدامهم للأجهزة الإلكترونية و النتائج المترتبـة على ذلك.

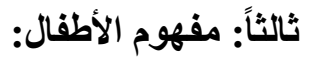

التعريف النظري: الطفل في اللغة الصغير من كل شيء عيناً كان أو حدثاً، فالصغير من أو لاد الناس و الدو اب طفل، و الصغير من السحاب طفل وجمع الطفل اطفال. (ابن منظور، 1412)

ويعرف اصطلاحاً بأنها المرحلة المبكرة من حياة الإنسان و التي يكون خلالها في اعتماد شبه تام على المحيطين بـه سواءً كانو ا أبوين أو أعضاء الأسرة أو المعلمين وهي التي تبدأ بالو لادة وتنتهي بالبلوغ. برها ويعرفها الباحث اجر ائياً بأنهم الأطفال الذين يدرسون في المرحلة الابتدائية ولم يتجاوزوا الثانية عثر عاماً. (العجمي، 2014) 
2. 2 الإطار النظري والدراسات السابقة

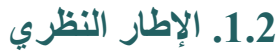

\section{المبحث الأول: الأجهزة الإكترونية}

يُعرف علم الإلكترونيات على أنّه علم يختصّ بالأجهزة الإلكترونيّة وكيفيّة عملها، والمبدأ الأساسي الذي يعتمد عليه هو سريان التيّار الكهربـائي في تلك الأجهزة، كمـا أنّه بهنمّ بتصميم الأجهزة الإلكترونيّة و القطع الأساسية التي تتكوّن منها، وتستخدم الإلكترونيات في مجالات عديدة مثل صناعة الر اديو و الحاسوب و غير ها.

\section{مفهوم الاجهزة الإكترونية:}

هي الأجهزة التي تستخدم في صناعتها مو ادو أدوات إلكترونيّة حديثة الصنع، وتمتاز بدقتها وسـهولة نركيبها وصيانتها؛ حنّى تستخدم في أداء وظائف معيّنة ومميّزة وينمّ استخدامها لاستنباط نتائج دقيقة ومعيّنة، حيث قام الإنسـان بسكب كافّة المعلومـات و المهار ات و التقنيات في إنتاج تلكك الأجهزة المميّزة التي تسـاعد الإنسـان، وكأيّ تطوّر تقنيّ فهو يحمل العديد من الأمور لهور الإيجابيّة التي ساعدت على ازدهار المجتمع والإنسان وتطوّر هما معاً، وتعمل على دعم الدول المنشأة لها لكي تسنطيع المنافسـة في سوق العمل حيث يتسنّى لمختر عيها تحقيق إنجاز ات عظيمة ترصد لهم، ومن ناحية أخرى فهي أيضـاً تحتوي على الإنى العوائق و الاتّجاهات السلبيّة التي تؤدي إلى تدمير المجتمع وتر اجعه فيما إذا استخدمها بشكلٍ خاطئ.

\section{أنواع تطبيقات الاجهزة الإكترونية}

\section{التطبيقات الأصلية:}

Apple ،Windows Phone) هي تطبيقات يتم برمجتها وتطوير ها لتتو افق مع احد نظم تشغيل الأجهزة الإلكترونية مثل Objective C ) (IOS, Google Android (Programing)، بينما يدعم نظام (Java Programming) للغة (أخير ا يدعم نظام (Windows Phone) للغة (Net Framework). تطبيقات الويب:

هي تطبيقات تستند على منصفح شبكة الويب للأجهزة الإكترونية في عملها، ويتطلب تو افر تقنيات شبكة الويب مثل (Javaو ومن اهم عيوب هذه الفئة هو محدودية وصولها إلى البيانات الأساسية ونظم تشغيل الجهاز الذكي المستخدم.

كما إنها تستغرق وقت إضافي في تحميل و عرض محتوياتها ووظائفها كونها تعتمد على سر عة اتصال الجهاز المستخدم بشبكة الويب، إلا هذه الفئة تميزت بكونها لا تشترط تجهيز ات محددة في الأجهزة الإلكترونية أو تتطلب من المستخدم تحميل تطبيقات

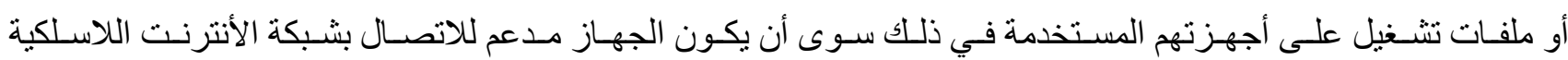

.(Wireless) 


\section{التطبيقات الهجينة:}

هي تطبيقات تحساول الجمع بين خصـائص ومميز ات كلا من التطبيقات الأصلية وتطبيقات الويب، بشكل يحقق توازن في اسـتخدامها وسـر عة تطوير هـا، فهـي تطبيقـات يـتم تصـميمها بلغـــ (HTML5) ويـتم إدر اجهـا داخـل نطـاق تطبيقـي أصـيل (Container Native) (الو اجهة فقط) في شكل تطبيق أصيل قابل للعمل و التشغيل عبر نظم الأجهزة الذكية. (الحربي، 2016)

\section{مميزات الاجهزة الإكترونية:}

\section{يوجد عدة مز ايا لهذه الاجهزة وهي:}

- - أتاحت للأفر اد أساسيات في حياتهم و أعمالهم، حيث لا يمكن الاستغناء عن هذه الأجهزة في جميع مجالات الحياة، فيتم

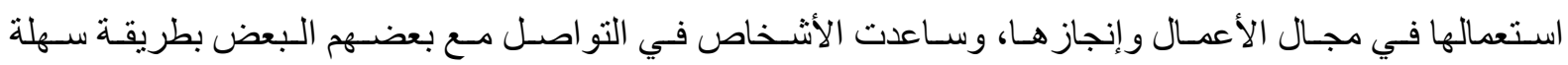
و اقتصادية.

- - تعمل الأجززة الإلكترونية توفير الوقت و الجهد في التعرف على المعلومـات التي يحتاجها الأفر اد من خلال تصفح شبكة الإنترنت و استقبال. - - تعمل الأجهزة الإلكترونية على تعليم الأفر اد على دمج مصادر التعلم وتكاملها فيما بينها، وتعين المتعلم على التفكير و التعلم بطريقة غير خطية، بل تشعبية بانتقاله السلس بين الموضو عات و التطبيقات و البر امج النشطة. - - تسـاهم الأجهزة الإلكترونيـة على إرسـال و استقبال الرسـائل النصية، واستقبال و إجـر اء المكالمـات الهاتفيـة، والتقاط وعرض الفيديوهات والصور وتخزينها، وتشغيل وتسجيل الموسيقى و الصوت. - - تساعد الأجهزة الإكترونية في التعرف على التاريخ و التوقيت و المنبه، وحول درجات الحرارة و الطقس، ويساعد في تدوين وكتابة الملاحظات، ويصدر أو امر صوتية. - - تتيح الأجهزة الإلكترونية العديد من التطبيقات المسلية و المسـاعدة للأفر اد التي منها القر اءة الإلكترونيـة، والمصباح البدوي، و الألعاب، و الآلة الحاسبة، وتثبيت التطبيقات المختلفة وتنزيلها. - - تسهل الأجهزة الإلكترونية على الأفراد معرفة أي موقع جغر افي بدقة عن طريق تحديد مكان التو اجد والتعرف على الطرق، كمـا توفر للمستخدمين إمكانيـة مشـاهدة الأفلام و الفيديو هات وسماع الموسيقى، وتحميل الألعـاب المختلفـة.

$$
\text { (اسماعيل، 2015) }
$$

\section{استخدام الأطفال للأجهزة الإكترونية:}

قد يرى الآباء أن استخدام الهو اتف الإلكترونية أو الأجهزة اللوحية بالنسبة للأطفال يقتصر على كونه وسيلة من وسـائل الترفيه

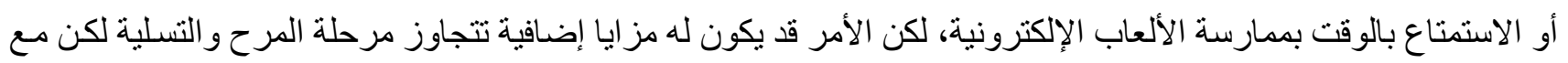
مر اعاة حدود الاستخدام الآمن الذي لايؤثر على البصر أو التركيز أو النشاط الدراسي. (عبد العاطي، 2015) 


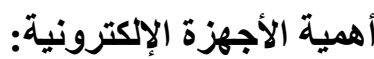

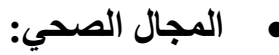

ظهرت مجمو عة من البر امج التي سهلت للمرضى المر اجعين وطلاب الطب. حيث أتاحت بعض الثـركات بر امجا تعمل على تنظيم مو اعيد تتـاول الأدويـة، و التـي تعدل على تذكير المريض بنوع الدو اءو والوقت الـلازم لتنـاول الدو اء فيـهـ كمـاظهرت تطبيقات أخرى توفر جهد الزيار ات المتكررة للصيدليات فالإمكان المسحُ ضوئياً على خطوط الثفرة الخاصـة بعلبة دو اء معين موجود في المنزل. ويتم إرسال طلب الثر اء فوراً إلى الصيدلية المعنية.

ويمكن كذلك لطالب الطب الوصول الى بعض المصطلحات من القواميس الطبيـة الخاصـة أو التـدرب ـ مثنال ـ على تشخيص صور الأشعة التقليدية وأيضاً على تقييم صور جهاز التصوير الطبقي المحوري وصور جهاز الرنين المغناطيسي) المِرنـان

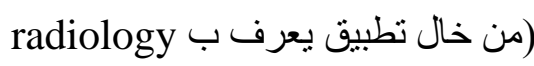

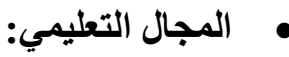

يمكن للمعلمين استخدام الأجهزة الإلكترونية كوسيلة تعليمية لعرض الكتب الكترونية أو مقاطع الفيديو والصور في الصف، كمـا تتيح للآباء التو اصل مع المعلمين لمعرفة مستوى أبنائهم وتقييم أدائهم الدراسي. و هناك بر امج خاصة أنشئت لتنظيم جدول الطالب الدر اسي - وخاصة طالب الجامعة _ للتذكير بمو اعيد المحاضر ات و أماكنها وللتذكير أيضا بالمهام و الو اجبات التي يجب أن يقوم بها الطالب، كالتطبيق المجاني الذي يمكن تحميله على أجهزة (iOS أو..

(Android

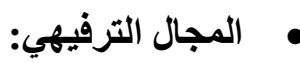

انتشرت مؤخر ا العديد من تطبيقات الألعاب الإكترونبة والتي تعددت مجالاتها بحيث تناسب مختلف الأعمـار والأهداف، فمنها ما هو للتسلية و الترفيه فقط، ومنها ما هو خاص بتعليم الأطفال بعض الأساسيات كالحروف و الأرقام و غير ها.

\section{إيجابيات وسلبيات الأجهزة الإكترونية:}

أصبحت التكنولوجيا جز ءاً لا يتجزأ من الحياة اليومية لأي طفل وهو مـا بطر ح عدة تساؤلات واختلفت الآراء حول ايجابيات

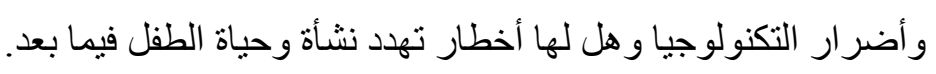

"أجريـت الكثير مـن الأبحـاث و النقاثــات على المسـتوى العلمي وحتى بين الآبـاء بعضـهم البعض حـول إيجابيـات وسـلبيات التكنولوجيا على الأطفال ودور الأهل في تجنب أخطار التكنولوجيا بل وتحويل سلبياتها إلى مميز ات تساعدهم في تربيـة وتعليم

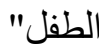

وقام الباحثون هنا بطرح أهم النقاط التي توصلو ا إليها فيما يتعلق بإيجابيات وسلبيات استخدام الأطفال للأجهزة الإكترونية. وكانت ايجابيات استخدام الأطفال للأجهزة الإلكترونية أنه يمكن استخدامها في مجال الدر اسـة والتعلم حيث يمكن تعليم الطفل الحروف و الأرقام من خلال البرامج المخصصة لذلك. 
كما أنها تقوم بتنمية مهارة الأسلوب التفاعلي لاى الطفل عن طريق بعض الالعاب التي تعلم الطفل طريقة الاستجابة و التفاعل المؤثرات الصوتية و البصرية. (اسماعيل، 2009).

\section{ومن أهم الفوائد التي تقدمها الأجهزة الإكترونية:}

- تقدم الطفل العلمي

ـ التواصل المستمر مع الطفل أثناء عدم تو اجده في المنزل

ـ تحمل المسؤولية

\section{عيوب الاجهزة الإكترونية:}

1- تسبب مشاكل صحية منها قلة النوم و الاستيقاظ عند نركها بجانب الفرد وهو نائم، لتو اجد إثعاعات مضرة على الدماغ

$$
\text { توثر على مادة الميلاتونين الخاص بالنوم. }
$$

2- تعمل على ارتفاع خطر الإصـابة بمرض السرطان لأنها تحتوي على المو اد المسرطنة التي تؤثر على المستخدمين من

$$
\text { خلال الإشعاعات التي تصدر منها. }
$$

3- تساهم في الأضر ار بعظام الأنسان، حيث تعمل على إصـابة الرسخ و الرقبـة و اليد، وذلك نتيجـة الحركة السريعة عند

$$
\text { الكتابة على الأجهزة الإلكترونية. }
$$

4- يؤدي استخدام وسائل التواصل الاجنماعي الذي يتم على الأجهزة الإلكترونية في الانشغال عن الأهل وقطع صلة

$$
\text { الرحم، أو التعامل معهم بشكل سطحي. }
$$

5- تضر الأجهزة الإلكترونية بالمر أة الحامل، حيث ينقل إشعاعات إلى الجنين الذي يؤثر عليه في نموهوسلوكه فيما بعد.

(المصري، 2018)

\section{المبحث الثاني: الطقولة}

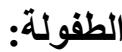

تعد مرحلة الطفولة المبكرة الخطوةَ الأولى في سلم النظام التعليمي، ومن أهم مر احل النمو الفكري و الجسدي و النفسي للأطفـال، فلسنو ات عدة كانت مرحلة رياض الأطفال قائمةً على مبدأ اللعب وتعلم بعض المهار ات الحياتية، ولكن مـع تسارع التغيرات الاقتصادية و التعليمية و الرقمية في عالم اليوم.

\section{مرحلة الطقولة:}

تعريف مرحلة الطفولة في علم الاجتماع، فإنها تلك المرحلة من حياة الطفل تبدأ منذ الو لادة وحتى سن البلوغ، امـا بموجب القانون فالثخص يكون بالغ في عمر الثامنة عشرة، حيث يكون مسؤول عن كل تصرفاته من الناحية القانونية. 
اما مرحلة الطفولة في علم النفس فهي تعرف بأنها تلك المرحلة التي تحتوي العديد من التطور ات التي تحدث للطفل في النمو، وحتى مرحلة المر اهقة، وفي مرحلة الطفولة يركز الاباء على بناء شخصية الطفل، من حيث بناء شخصيته الاجتماعية و النفسية السوية، وينتج عن هذه التربيـة النفسية والاجتماعيـة السوية شخص سوى صـالح للمجتمع، منو افق نفسيا مـع ذاته كذللك مـع

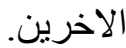

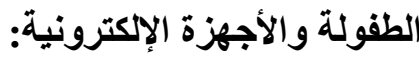

\section{تعريف مرحلة الطفولة:}

مرحلة الطفولة هي المرحلة التي تبدأ للإنسان منذ و لادته إلى أن يصل إلى سن البلوغ، هي المرحلة التي يتعلم فيها الإنسـان السلوكيات ويمارس التطورات ويكون الأفكار عن الحياة من حوله، حتى يستعد لمواجهه العالم الكبير الذي يتخطى حاجز البيت مثل المدرسة أو العمل، ويطلق أيضا على مرحلة الطفولة إنها المرحلة التي ينمو فيها الطفل بشكل منطور حتى يصل لمرحلة المر اهقة، وفي هذه المرحلة يكون مسؤول من الو الدين حتى يقوم بيناء شخصيته منذ الطفولة، لذلك يجب على الأم والأب مساعدة طفلهم حتى يصبح طفل مشارك في المجتمع وسوي نفسياً. تعريف الطقولة:

يُقصَد بالطفل لغةً: الجزء من الثيء، و هو المولود ما دام ناعماً دون البلوغ، وهو أيضاً أوّل حياة المولود حتى بلو غِه، ويُككن

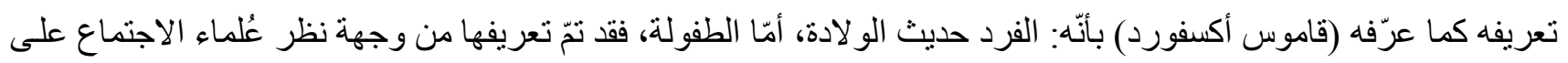

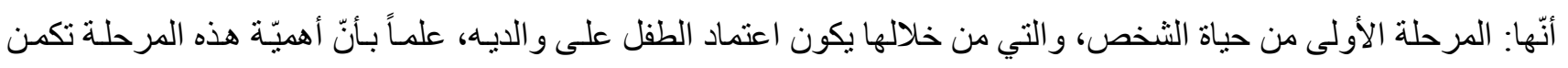

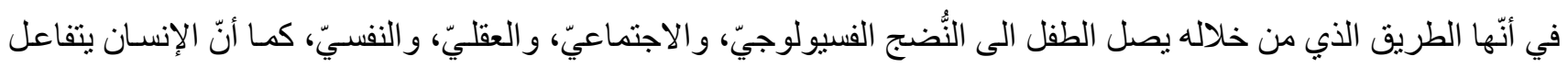
اجتماعيّاً من خلالها مع البيئة المُحبطة بـاه.

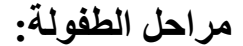

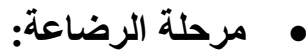

و هذه المرحلة تبدأ مع الطفل منذ لحظة الو لادة وحتى نهايـة مرحلة الرضـاعة، اي حتى عمر الطفل الثاني، وفي خـلال هذه

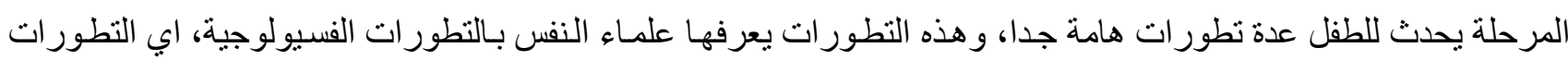
العاطفية، حيث يتفاعل الطفل خـلال هذه المرحلة فقطمع الام، ويرتبط بها عاطفياً، حيث تعتبر هي مصدر الحنـان والامـان

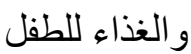

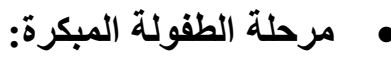

وهي مرحلة رياض الاطفال، وهي مرحلة تسبق دخول المدرسة، وهي تبدأ منذ عمر الطفل الثالثة وحتى عمر السادسـة، وتتميز هذه المرحلة ببطيء نمو الطفل عن اي مرحلة اخرى، وفي خلال هذه المرحلة يكتسب الطفل مهار ات عديدة اهمها مهارة التو اصل مع الاخرين، حيث في هذه المرحلة تزداد حصيلة الطفل اللغوية، 
ويكتسب الطفل خلال هذه المرحلة مهارة التعامل مع من حوله مع زيادة الحصيلة اللغويـة للطفل، وكذلك تترسخخ عنده بعض المهار ات الاجتماعية في التو اصل مع الاخرين، ويبدأ الطفل يميز بين الخطأو الصواب.

رحلة الطفولة المُبكِّرة اتَّقتق العُلماء على أنّ هذه المرحلة تبدأ في عُمر 3 سنوات لاى الطفل، وتستمرٌّ إلى عُمر 5 سنوات، حيث

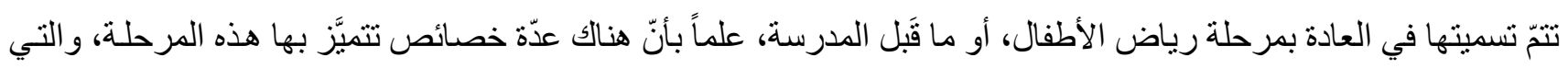
يمكن تلخيصها على النحو الآتي:

- - النمو الجسميّ: في هذه المرحلة يزداد طول، ووزن الطفل، حيث يتر اوح مُعدَّل طوله مـا بين 90-120سم، ويزداد

$$
\text { وزنه بمُعدَّل كيلو غر امِ واحدٍ في السنة. فئ. }
$$

- - النموٌٌ الحركيّ و الحسبي: في بداية هذه المرحلة يكون النموٌ الجسميّ غير مُتناسِقٍ؛ وذلك بسبب عدم وصول الطفل إلى

$$
\text { النُّضج في العضلات الدقيقة. }
$$

- - النمو الفسيولوجيّ: يسنطيع الطفل في هذه المرحلة ضَبْط عمليّات الإخر اج لديه (التبوُّل) - - النمو العقلي: وفي هذه المرحلة يبدأ الطفل بالتحدُّث بشكلٍ جيّدٍ؛ ولذلك تبدأ أسئلته بـالظهور، كمـا أنّه يكون اجنماعيّاً

$$
\text { يُحبُّ الاختلاط، والتعرُّف على الاخرين }
$$

- النمو الانفعاليّ: وفي هذه المرحلة يُعبّر الطفل عن بعض مشـاعره، مثل: الغضب، و الخوف، عن طريق الاستجابات

$$
\text { الجسميّة }
$$

\section{• مرحلة الطفولة الؤسطى:}

ثُسمَّى هذه المرحلة بمرحلة الطفولة الهادئة؛ وذللك بسبب انخفاض مُعدَّل النموٌٌ الجسديّ لدى الطفل مُقارنـة بالمر احل السـابقة، وتبدأ هذه المرحلة من سنّ 7 سنوات إلى سنّ 12 سنة، وقد تمّ تصنيف هذه المرحلة في بعض الكُتب ضمن مرحلنَّن: الأولى

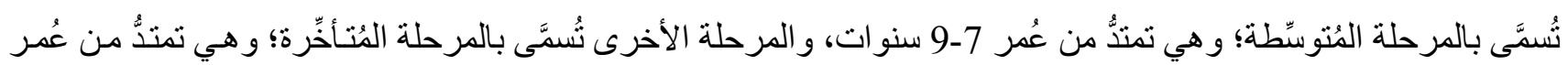

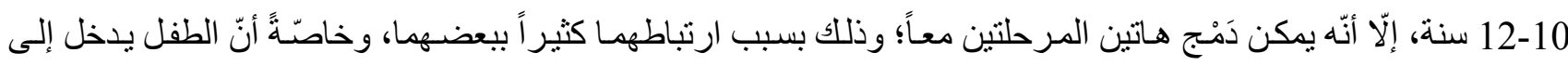
المدرسة، ويبدأ النموٌٌ المُتسار ع لديه في الجو انب جميعها، وفيما يلي نذكر أهمّ الخصائص التي تُمبِّز هذه المرحلة:

- - النموُ الجسميّ: إنّ من أبرز ما يحدث خلال هذه المرحلة هو استبدال الطفل لأسنانه اللبتَبِّة بالأسنان الدائمة، إضافة إلى

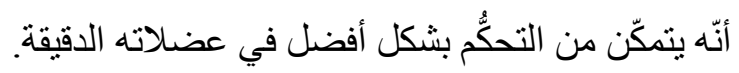

- - النموُ الفسيولوجيّ: في كلّ مرحلة يتقدَّم فيها الطفل بالعُمر، تبدأ ساعات نومه تقلُ تدريجيّاً، و على العكس من المرحلة

$$
\text { السابقة. }
$$

- - النموٌُ الحسِّي: يبدأ النموٌٌ اللغويٌٌ في هذه المرحلة بالتسارُع؛ بسبب دخول الطفل في سنّ المدرسة، ممّا يمكّنه من معرفة

$$
\text { الحروف الهجائيّة، وتمييز الأعداد، و إدراك الألوان. }
$$

- - النموٌُ العقليّ: بما أنّ الطفل بدأ في دخول المدرسة، فإنّ النموّ العقليّ لديه يزداد تدريجيَّا، ممّا يُؤدّي إلى ازدياد الحصيلة المغيّة ل الديه. 
- - النموٌ الانفعاليّ: يتمكَّن الطفل من التعبير عن مشـاعره عندما يَصلُ إلى هذه المرحلة؛؛ ولذلك فإنّه يكون قادراً على

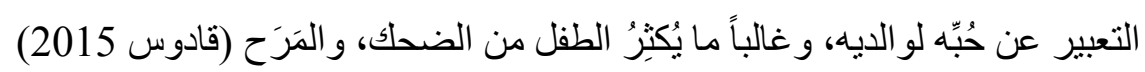

\section{• مرحلة فترة ما قبل المدرسة:}

تشـل هذه المرحلة مـاوصفناه سـابقًا بالمرحلة الثانيـة من الطفولة المبكرة. يبدأ الأطفال في استخدام المهار ات العقلية التي تساعدهم على تكوين علاقات مع أقر انهم و التفاعل مع الآخرين بقدر أقل من الأنانية.

في هذه المرحلة يبدأ إنتاج الميالين في الدماغ، وهو أسـاس تطور التفكير المجرد، و الذي يجعل الطفل أكثر قدرة على حل المشكلات و التمييز بين السلوك الصحيح و الخـاطئ واتبـاع الأعر اف و القيم و التو اصل مـع الآخرين و القيام بمهام أكثر تعقيدًا.

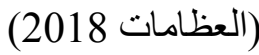

\section{• مرحلة فترة المدرسة:}

هي المرحلة الأخيرة من الطفولة، وتمتد من 6 إلى 12 سنة (يمكن تسميتها مرحلة الطفولة الثانية)، وتبدأ بعدها فترة المر اهقة. في هذه المرحلة على وجه التحديد، يكون الأطفال قادرين على استيعاب مفاهيم أكثر تعقيدًا وتجريدًا للعالم، واستخدام مهارات التو اصل الثفوي و الكتابة بشكل أفضل، و التحكم في حركات الجسم، وفهم مشاعر الآخرين وتحليل المو اقف المختلفة و التركيز

$$
\text { واتخاذ قرار ات مناسبة. }
$$

\section{• مرحلة الطقولة المتأخرة: (المراهقة)}

و هذه المرحلة تبدأ بعد عمر التاسعة وحتى عمر الثانية عشرة، وفي خلال هذه المرحلة ينتقل الطفل من مرحلة الطفولة الى مرحلة البلوغ، وخلال هذه المرحلة يتعلم الطفل المهار ات الحياتية التي تفيدة في مستقبلة، ويكتسب بعض المهار ات السلوكية و التي تتحكم في تصرفاته في الكبر.

\section{أهمية مراحل الطقولة:}

هذه الفترة من حياة الطفل تكون هامة جدا حيث يكتسب فيها الطفل بعض المهار ات الهامـة في حياته، بل وفيها يكتسب ايضـا الطفل العادات و الاخلاق و القيم التي يعيش عليها باقي عمرة، لهذا فإن هذه المرحلة تعتبر مرحلة هامة جدا في حياة الفرد، حيث يترتب على هذه المرحلة اما شخص سوي او شخص مريض، شخص ملتزم خلقيا او شخص غير ملتزم اخلاقيا.

كما تعتبر مرحلة الطفولة من المر احل العمرية الهامة بالنسبة لأي طفل، حيث يكتسب فيها بعض الخبرات الحياتيـة التي نؤثر في بناء شخصيته، بالإضافة إلى اكتساب بعض المهار ات التي تساعده في حياته مثل:

$$
\begin{aligned}
& \text { 1. معرفة الطفل بعض العادات و التقاليد التي يعيش عليها المجتمع من حوله من خلال الأب و الأم. } \\
& \text { 2. تعلم قيمة الأخلاق، وكيف يصبح الطفل ملتزم أخلاقيا حتى يؤثر في المجتمع عند الكبر. } \\
& \text { 3. يتعلم الطفل كيف يكون شخصياً سوى ملتزم عن طريق تربية الأهل. (هاتم 2019) }
\end{aligned}
$$

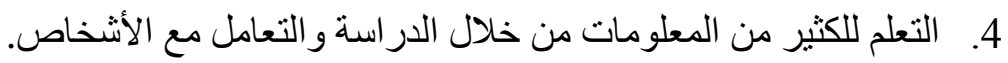




\section{حاجات الطقل الهامة:}

في السنو ات الأولى من العُمر، وخصوصاً من فترة الحمل وحتى سنّ الثالثة، يحتاج الأطفال إلى التغذيـة والوقايـة والتحفيز من

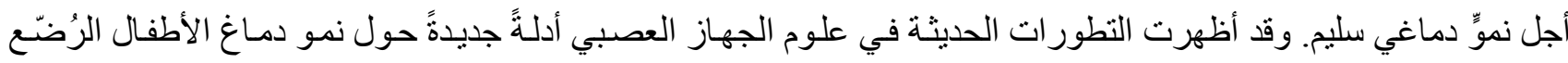
خلال تللك الفترة. وبالتالي، نعلم أنه في السنوات الأولى من حياة الأطفال، نتكل أدمغتهم روابط جديدة بمعدل مذهل يبلغ (وفقاً لمركز نمو الطفل التابع لجامعة هارفارد) أكثر من مليون رابطة في الثانية؛ وهي سرعة لن تتكرر لاحقاً قط.

\section{بعض مشاكل الطفولة:}

- - الكذب: بعض الأطفال يقومون بالكذب بسبب الخوف من العقاب إذا ارتكب الطفل بعض الأخطاء أثناء يومـه، وهنالك

$$
\text { بعض الأطفال يلجؤون للكذب للحصول على المنفعة أو على أي شيء يريده. }
$$

- - العزلة: العلاقة الأسرية بين الطفل و أهلـه تؤثر على شخصية الطفل، فهناك بعض الأطفال الذين يتعلمون التفـاهم و الانفتاح بين الأسرة والمجتمع، و هؤلاء الأطفال الذين يتعوذون على الحديث دائمـا والخروج من المنزل مـع أهلهم، و عندما يتعرض الطفل إلى العزلة من أهله أو عدم مشاركة أهله في الحديث أو الخروج، بسبب بعض العزلـة للطفل، ويجعله غير اجتماعي مما يؤثر على شخصبيته بالسلب. - التبول اللاإر ادي: في بعض الأحيان يتعرض الطفل للتبول اللاإر ادي لفترات تختلف في طولها وقصر هاو هذا يمكن أن يتعرض له الطفل بسبب أشباء كثثرة يمكن أن تكون سبب نفسي التوتر والقلق أو سبب مرضى لذلك يجب استشـارة الطبيب لمعرفة السبب الرئيسي و إمكانية علاجه.

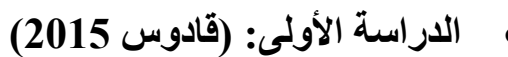

هدفت الدر اسة إلى مدى تـأثير الاعـلام المرئُي على غرس القيم الأخلاقيـة لدى الأطفـال مـا قبل الدراسـة فكانت عينـة الدراسـة الأطفال مـا قبـل سـن المدرسـة ( 4- 6) ومـن النتائج التي توصـل اليها الباحث أهميـة استخدم المقاطع المرئية على شانــات التلفزيون لتعديل وضبط المفـاهيم و السـلوكيات الإيجابيـة وتوجيههـا لدى الأطفال لأنـه يحظى بميزة ينفرد بهـا لدى جمهوره وبخاصةً الأطفال هي أنه يجمع بين الصوت و الصورة و الحركة في آنٍ واحد ما يقضي الطفل اما شاثنات التلفزيون لفترة طويلـة فيجب استغلال ذلك بشكا إيجابي وتوجيه البر امج الإعلامية الموجه للطفولة بشكل يضمن زرع القيم الأصيلة .

\section{• الاراسة الثانية: (متولي 2017)}

هدفت هذه الدر اسة إلى بحث أثر ألعاب شاثنـات اللمس على أنشطة الطفل ونموه في مرحلة الطفولة المبكرة من وجهة نظر

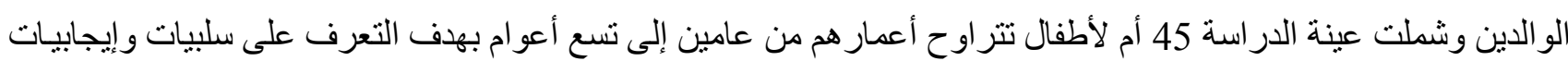


ألعاب شانشات اللمس من وجهة نظر هن، وتحديد منوسط عدد الساعات التي يقضيها الأطفال مع تلك الألعاب ومن النتائج أيضـاً تأثنير ألعاب شاثنات اللمس على نشاط الطفل البدني ومن ثم نمو العقل المعرفي.

\section{• - م الدراسة الثالثة: (عبدالعال 2019).}

هدفت هذه الدر اسة إلى التعرف على مدى ارتباط إدمان الألعاب الإلكترونية على بعض الأمر اض الاجتماعية للمر اهقين أفراد العينة البحنية وكذلك التعرف على الفروق بين الذكور و الإناث وفقاً لمدى انتشار الأمر اض الاجتماعية و النفسية للمر اهقين أفراد العينة البحتية، ولتحقيق أهداف هذه الدر اسة تم اختبار عينة عمدية بلغ حجمها 47 طالباً من متمرسي الألعاب الإلكترونيـة ( 27 طالب، 20 طالبة ) بمرحلتي الإعدادية والثانوية بإحدى قرى محافظة دمياط وتوصلت الدر اسة لعدة نتائج أهمها : وجود علاقة ارتباطية سالبة بين متغير ات المساندة الاجنماعية من قبل الاسرة وكل من درجة إدمان الألعاب الإلكترونية والعزلة الاجتماعية، و العنف لـى المر اهقين، وجود علاقـة ارتباطية موجبة بين درجـة إدمـان الألعـاب الإلكترونيـة وبعض الأمر اض الاجتماعية

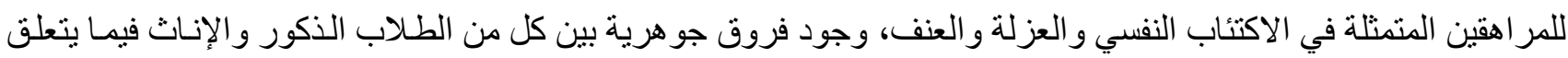

$$
\text { بالاكتئاب النفسي. }
$$

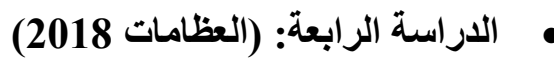

هدفت الدر اسة إلى التعرف على التأثثر السلبي لوسائل الاتصال الحديثة على تربية النشء من وجهة نظر أولياء أمور الطلبة، و أظهرت النتائج وجود تأثبر سلبي لوسائل تكنولوجيا الاتصال على تربية النشء من وجهة نظر أولياء الأمور وبدرجة مرتفعة،

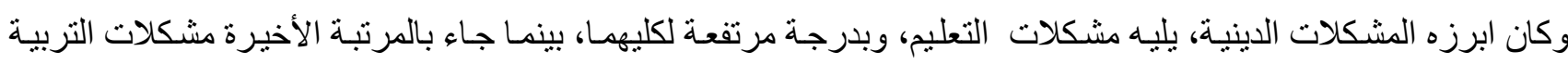
المجتمعية وبدرجة منوسطة، ووجود فروق دالة إحصائياً في استجابات أولياء الأمور ككل تبعاً لمتغير العمر لصسالح الفئات (49- 35، و أكثر من 50 سنة ) وفروق في استجابات أولياء الأمور ككل تبعاً لمتغير المؤهل العلمي لصـالح فئات التعليم

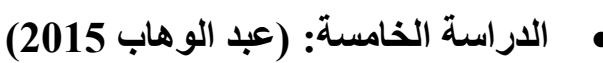

هدفت الدر اسة إلى رصد أهم مو اقع التو اصل الاجتماعي التي بستخدمها الطفل السعودي بالإضـافة إلى معرفة أنماط استخدامه لها و الوقوف على دو افع و أسباب استخدامه لتلك المو اقع ومن ثم معرفة الإشـاعات المتحققة من متابع مواقع التو اصل الاجتماعي ومدى وعي الطفل السعودي بنأثير مو اقع التو اصل الاجنماعي ونوصلت إلى النتائج التالية: ارتفاع معدلات تصفح الانترنت من قبل الأطفال عينة الدر اسة وهو ما يلتقي بالاتفاق مع نتائج الدراسات السابقة، جاء ترتيب مواقع التو اصل الأكثر ارتياداً من قبل

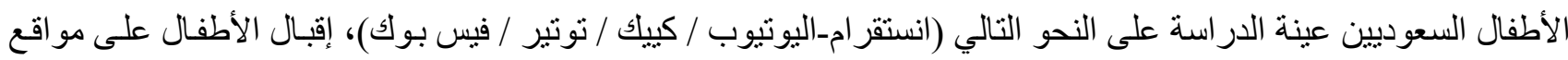
التو اصل الاجتمـاعي لـه تأثثيره على الأنشطة الاجتماعية والاتصـالية الأخرى (ممارسـة الرياضـة، مشـاهدة التليفزيون، قر اعة القصص، اللعب، الخروج مع الأهل).

\section{• الاراسة السادسة: ( الهدلق 2013).}

هدفت الدر اسة إلى التعرف على إيجابيات وسلبيات الألعاب الإلكترونيـة ودو افع ممارستها من وجهة نظر طلاب التعليم العام

$$
\text { بمدينة الرياض، و استخدمت المنهج الوصفي، }
$$


وطبقت الدر اسة على ( 359) طالب وتم إعداد استبانة موزعـة على محاور الدر اسـة الثلاثنة وتوصلت إلى عدد من النتائج أهمها: هنالك عدد من العو امل التي تدفع طلاب التعليم العام لممارسة الألعاب الإلكترونية مثل السـعي للفوز و المنافسـة و التحدي وحب الاستطلاع، الألعاب الإلكترونية تسهم في تحسين بعض المهار ات الاجتماعية والأكاديمية لاى اللاعبين مثل مهارة البحث عن المعلومـات ومهارة التفكير الناقد ومهارة حل المشكلات، الآثار السلبية للألعاب الإلكترونية تم تصنيفها إلى ست فئات أضر ار دينية وسلوكية و أمنية وصحية و اجتماعية و أكاديمية و عامة .

\section{• الار اسة السابعة: (هاشم 2019)}

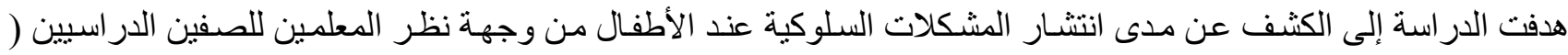
الخامس و السادس ) في المرحلة الابتدائية في محافظة النجف في ضوء استعمال الأجهزة الإلكترونية، ومعرفة مدى إمكانيـة التنبؤ بالمشكلات السلوكية عند الأطفال من وجهة نظر المعلمين وتوصلت الباحثة إلى مجموعة من النتائج أهمها: أنه يمكن التنبؤ بالمشكلات السلوكية عند الأطفـال مستعملي الأجهزة الإلكترونيـة في ضـوء الوقت الذي يقضبه الطفل عند استعماله للأجهزة الإلكترونية و النوع، و لا يمكن التنبؤ بالصف الدر اسي ومنها أيضاً أنَّ التكنولوجيا تؤثر في سلوك الأفر اد سلباً و إيجاباً، سيما عند الأطفال، الوقت الذي يقضيه الطفل في استعمال الأجهزة الإلكترونية والنوع لهما أثر في حدوث المشكلات السلوكية

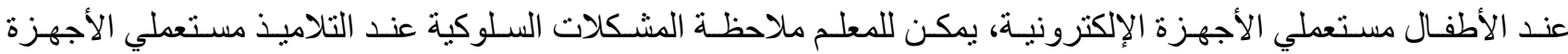

\section{• • الدراسة الثامنة: (الصقعبي 2015)}

هدفت هذه الدر اسة إلى الكثف عن و اقع استخدام الأجزة الإلكترونية من قبل الأطفال و الوقوف على إيجابيات وسلبيات استخدام الأجهزة الإلكترونية وأثر ها على الحوار و التو اصل مع الطفل من وجهة نظر الآباء و الأمهات، في حين تكونت عينة الدر اسة من عينه ضمت 200 من أولياء الأمور (الآباء و الأمهات) و استخدمت الاستبانة كأداة للار اسـة، كما توصلت الدر اسة إلى عدة نتائج من أهمها : أن الطفل يفضل البقاء مع الأجهزة الإلكترونيـة على الجلوس مـع العائلة، وأن الأجهزة الإلكترونية تؤثر على التحصيل الدر اسي للطفل وتضـف مـن الحوار و التواصل مـع الأسرة، ثم ختمت الدر اسـة ببعض التوصيات التي يمكن أن تكون إضـافة لبنـاء حوار وتو اصـل إيجابي مـع الطفل وتسـاهم في الحــ من الاستخدام السلبي للأجهزة الإلكترونية من أهمها:

تعزيز دور الأسرة في تحديد سلوك الطفل وعاداته في استخدام الأجهزة الإلكترونية، بتوجيه ميوله نحو التفكير الإيجابي و الاتجاه نحو العلم والمعرفة، ونشر التوعية الأسرية وتثقيف الأسر ببيان الطرق الصحيحة للاستخدام الأمثل لهذه الأجهزة من أجل التقليل من آثار ها السلبية على الأطفال.

\section{• الاراسة التاسعة: (العبودي 2008)}

تهدف الدر اسة إلى التعرف على مستوى القلق لاى الأطفال من مستخدمي الألعاب الإلكترونية و التعرف على دلالة الفروق في القلق بين الأطفال الذكور من ممارسي الألعاب الإلكترونية و غير الممارسين، واقد اسفرت نتائج الدر اسة على أن: 
- عينة الممارسين ظهرت عليهم أعر اض قلق عند مقارنتهم بغير الممارسين

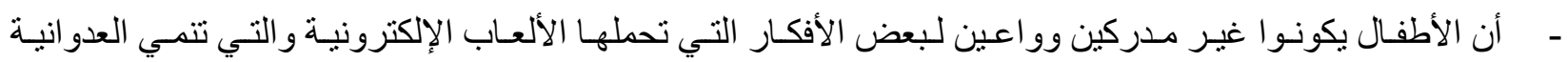
وتجعلهم يكتسبون سلوكيات مثل العنف.

\section{م الاراسة العاشرة: (قويدر 2012)}

هدفت الدر اسة إلى معرفة واقع الألعاب الإلكترونية بين أوساط الأطفال الجزائريين، ومحاولة الوصول إلى الكثف عن مختلف الجو انب المحيطة بهذه الظاهرة قصد المساهمة في الحد من شدة عنفو انها كخطوة أولى، و أسفرت الدر اسة عن: - للألعـاب الإلكترونيـة تأثير على سلوك الأطفـال فهي تعمل بتخطبط من صـانعيها على زرع السلوك العدو اني في شخصية الطفل. ـ تتامي السلوك العدو اني لاى الطفل جر اء الممارسة المتكررة لهذه الألعاب يجعله فرد يميل للجريمة و القتل بطريقة لا شعورية. - خطورة الألعاب على السلوك و القيم و التقاليد والدين، وتكوين أجيال تتميز بالعنف و العدو انية.

\section{الاراسة الحادية عشر: (هاله جميل وآخرون 2017)} يهدف البحث إلى در اسة استخدام أطفال مرحلة التعليم الأساسي لوسائل التكنولوجيا الحديثة وعلاقتها بسلوكهم العدواني، وتحديد مسـتوى و عـي الأطفـال باسـتخدام وسـائل التكنولوجيـا الحديثة بمحساوره الثلاثـة (اتجاهـات_ممارسـات ـ معلومـات ) و السـلوك

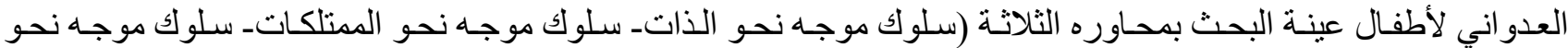
الآخرين. ومن أهم النتائج التي أسفر عنها البحث:

- وجود علاقة ارتباطية سالبة دالة إحصائياً بين وعي الأطفال بوسائل تكنولوجيا الاتصال و السلوك العدو اني للأطفال. - وجود علاقة ارتباطية موجبة دالة إحصائياً بين بعض متغير ات المستوى الاجتماعي و الاقتصـادي (عدد أفر اد الأسرة - دخل الأسرة) و إجمالي الوعي بوسائل تكنولوجيا الاتصال. ـ وجود علاقة ارتباطية سالبة دالة إحصائياً بين بعض متغير ات المستوى الاجتمـاعي والاقتصـادي (عدد أفر اد الأسرة، مستوى تعليم الو الدين، دخل الأسرة) و إجمالي السلوك العدو اني للأطفال. ـ ـ ـ وجود فروق دالة إحصائياً بين منوسطي درجات الذكور و الإناث في إجمالي السلوك العدو اني وذللك لصالح الذكور.

\section{الاراسة الثانية عثر: ( الثحروري 2007 )}

الدر اسة بعنوان أثر الألعاب الإلكترونيـة على العمليات المعرفية والذكاء الانفعـالي لدى أطفال مرحلة الطفولة المتوسطة في الأردن 2007، وتتحور إثكاليتها حول استقصاء أثر اللعاب الإلكترونية على العمليات المعرفية والذكاء الانفعالي لدى أطفال مرحلـة الطفولـة المتوسطة في الأردن، وأظهرت نتـائج الدراسـة أن هنـالك فروقـاً ذات دلالـة إحصـائية على مقيـاس العمليـات المعرفية بين المتوسطات الحسابية البعدية المعدلة تبعاً لمتغير المجموعة ولصالح المجموعة غير الموجهة. 


\section{الاراسة الثالثة عثر: (الهذلي 2014) ـ}

الدر اسة بعنوان أثر الألعاب التعليمية الإلكترونية في تنمية بعض المفاهيم العلمية لدى طفل ما قبل المدرسة، فقد هدفت الدر اسـة إلى الكثف عن أثر الألعاب التعليمية الإلكترونية على تتمية بعض المفاهيم العلمية لدى الأطفال ما قبل المدرسة، بمحافظة الليث

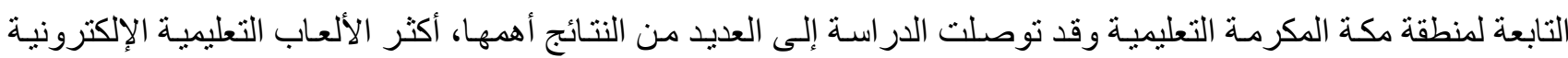
تفضيلاً لدى عينة البحث هي: أو لاً الألوان، جسم الإنسان، الحيو انات وصغار ها، صح أم خطأ، وظائف الأعضاء. ثانياً: المفاهيم العلمية المناسبة لطفل ما قبل المدرسة والتي يمكن تتميتها باستخدام الألعاب التعليمية الإلكترونيـة هي: الألوان، الوقت، جسم الإنسان، حالات المادة، الحيو انات وصغار ها، صوت وصورة الجمع، صح أم خطأ، وظائف الأعضاء.

ثالثاً: توجد فروق ذات دلالة إحصـائية عند مستوى 0.05 بين متوسطي درجات المجمو عـة الضـابطة (التي درست بالطريقة المعتادة ) و المجمو عـة التجريبيـة ( التي درست باستخدام الألعاب التعليمية الإلكترونيـة) في التطبيق البعدي لاختبار المفاهيم العلمية لدى أطفال ما قبل المدرسة بعد ضبط أثر الاختبار القبلي لصالح المجموعة التجرييية.

\section{• الدراسة الرابعة عشر: دراسة الصباح (2015)}

هدفت الدر اسة إلى معرفة التحديات والتغير ات التي يعانون منها الولدين مع أبنائهم الذين هم في سن مبكر من عمر هم، واتبعت

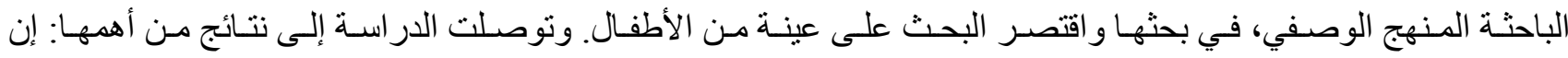
مستخدمين الأجهزة الإلكترونية من الأطفال تغير أسلوب حياتهم و أصبح أسلوب حياة خاطئ و هذا ما يو اجه الو الدين من تحدي الـي لتغير هذا السلوب.

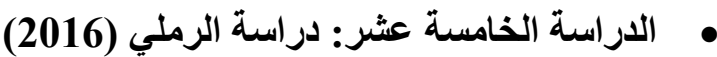

التي وضحت أهم التحديات التي تو اجه الآباء مع أبنائهم عند استخدام الأجهزة الإلكترونية، و اقتصرت على عينـة من المجتهع وهم الأطفال في سن مبكر. توصلت الدراسة الى نتائج من أههها: استخدام الطفل للأجهزة الإلكترونيـة حتى في أوقات الطعام، فقدان الثعور بالأشياء المهمة من حوله. وهذه تعد أكبر التحديات التي تو اجه أولياء الأمور.

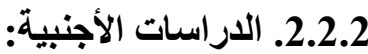

\section{• الاراسة الأولى: (hysing M,pallesen S,stormark KM 2014).}

تم إجر اء هذه الدر اسة في النرويج وقد شملت العينـة 9846 مر اهق بأعمـار تتر اوح بين 16 إلى 19 حول استخدام المر اهقين لأجهزتهم الإلكترونية في الليل و النهار وتأثير ها على نومهم خلصت الدر اسة إلى أنَّ المر اهقين يقضو اوقت طويل في استخدام الأجهزة الإلكترونية والتي تتسبب في تقصير مدة نومهم و أن هنـاك علاقة سلبية بين استخدام الأجهزة الإلكترونية وبين فترة 


\section{• (Sundus M, 2018 (الدراسة الثانية: (}

هدفت الدر اسـة إلى التعرف على تأثثير استخدام الأدوات الإلكترونية على الأطفال، حيث اظهرت الدر اسـة بعض التأثنيرات السلبية على قدرة الأطفال على الكلام وتأخر اللغة لديهم وضعف في مهار ات التو اصل وأيضـاً قد تتسبب في التأثثر السلبي على شخصيتهم كتجربة القلق العصبي و الخجل و الخوف وفي جانب آخر ذكرت الدراسة أنَّ الأطفال بتعلمون الكثير من الأشياء السلبية قبل عمر 5 سنوات بالرغم من ذلك أظهرت الدر اسة بعض الجوانب الإيجابية من استخدام الأدوات الإلكترونية كالمهارة الحركية التي نرتبط مع العضلات عمد استخدام أيديهم و أصابعهم بشكل أفضل بطريقة فعالة جداً وفي وقت قصير، و أيضـاً تسـاعد استخدام هذه الأدو ات الإلكترونية على تطوير أسرع و أفضل للمهار ات المعرفية لدى الأطفال مثل التطبيقات التفاعلية و ألعاب الفيديو.

\section{• الدراسة الثالثة: (Cain N, Gradisar M,2010).}

استعرضـت هذه الدر اسـة بعض الأبحـات التـي اجريت حول العلاقـة بين استخدام الوسـائط الإلكترونيـة و النوم عند الأطفـال و المر اهقين في سن المدرسة وجد أنَّ استخدام الوسائط الإلكترونية يؤدي إلى ساعات نوم أقل وتأخير في وقت النوم. وأنَّ 97 \% من الأمريكيين يملك على الأقل احدى الأجهزة الإلكترونية في غرفة نومهم. وأثـاره الدر اسـة إلى أنَّ هناك زيسادة في استخدام الألعاب الإلكترونية و الهو اتف المتنقلة والتي تلعب دور في هجرة النوم.

• الدراسة الرابعة: (Subrahmanyam, K., Greenfield, P., Kraut, R., \& Gross, E. (2001).

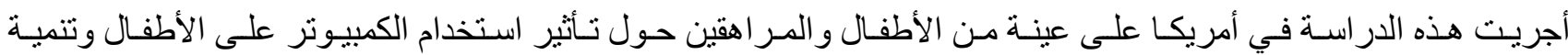
المر اهقين، و أظهرت أنه يؤدي استخدام الكمبيوتر والإنترنت على المدى الطويل إلى تحسينات طويلـة المدى في المهار ات المعرفيـة والإنجـاز الأكاديمي و إنَّ الاستخدام المعتدل للكمبيوتر لا يؤثر سلباً على المهار ات والأنشطة الاجتماعية للأطفال. و على الرغم من الاتجاهات الأخرى لاستخدام الكمبيوتر، تضل ألعاب الكمبيوتر الأكثر شعبية بين الأو لاد.

• الاراسة الخامسة: (Smahel, D., Wright, M. F., \& Cernikova, M 2015 )

هدفت هذه الدر اسة لمعرفة تأثثر التكنولوجيا على الصحة البدنية والعقلية من وجهت نظر الأطفال. وشملت هذه الدراسة الأطفال الذين تتر اوح أعمار هم بين 16-6 سنه في تسع دول أوربية (العدد=368). من خـلال مجموعات التركيز و المقابلات، وقد تم سؤال الأطفال عما بعتبروه أمر اً سلبياً أو إثكالاً أثناء استخدام الإنترنت و التقنية. وقد أظهرت النتائج في هذه الدر اسة، أنَّ الأطفال أبلغوا عن عدة مشـاكل جسدية كمشـاكل في العين و الصداع و عدم تتـاول الطعام و التعب. و أعر اض الصحة العقلية كالعدوان، مشاكل النوم، و أفاد الأطفال بمدى الإدر الك للأحداث عبر الإنترنت.

\section{التعليق على الاراسات السابقة:}

اوضـت در اسـة الصباح (2015) أسلوب التغيير في حياة الطفل، واستخدمت المنهج الوصفي في در استها، مثنل الدر اسـة الحالية. امـا دراسة الرملي (2016) اوضحت اهم التحديات التي تواجهه أولياء المور مـع أبنائهم، ولم تذكر المنهج المتبع في در استها. بحيث ان جميع الدراسات السابقة طبقت على الأطفال في سن مبكر ، و اتفقت الدر اسة الحالية مع الدر اسات السابقة. 
كمـا وضـحت در اسـة الصباح (2015) على مستوى دولة فلسطين، امـا در اسـة الرملي (2016) فتمت على مستوى الأردن وخاصة مدينة عمان، واختلفت الدر اسة الحالية عن الدر اسـات السـابقة بحيث تم تطبيق الدر اسـة على مسنوى المملكة العربية السعودية وخاصة بمحافظة جدة. اوضحت در اسة المزرو عي (2015) التي أوضحت استر اتيجية توظيف الأجهزة الإلكترونية في مجال تعليم الطفل، والتي اتبع فيها المنهج التجريبي، و اقتصر بحثه على عينة من الأطفال في سن مبكر. ونوصلت الدر اسة الى نتائج من أهمها: توسيع مدارك المعرفة عند الأطفال، تحفيز الطفل و اندفاعه لعملية التعليم.

و أنتـارت در اسـة كير كوريـان (2013) لاستر اتيجية توظيف الأجهزة الإلكترونيـة في اكتسـاب الأطفال للمهار ات عن طريق شاثشات اللمس مثل: مهارة الحفظ السريع، مهارة التحدث بطلاقة، مهارة تحليل الأسباب. و اتبعت في بحثها المنهج الوصفي، و اقتصر بحثها على عينة من الأطفال في سن مبكر. وتوصلت الدر اسة إلى نتائج من أهمها: تتمية الطفل فكريـا، إدر الك الطفل ل لما يجري من حوله.

تتاول هذا المحور الدر اسات السابقة المتعلقة بالاستر اتيجيات المتبعة لكي يصبح استخدام الطفل للأجهزة الإلكترونية أكثر فعاليـة و التي يتضح من خلال ما يلي:

- در اسة المزروعي (2015) حيث ركزت على استر اتيجية توظيف الأجهزة الذكية في التعليم، واتفقت الدراسـة الحالية مع الدر اسات السابقة في كيفية توظيف الأجهزة الإلكترونية. - من حيث المرحلة التي طبقت عليها الدر اسة نجد ان جميع الدر اسات السابقة طبقت على الأطفال في سن مبكر، و اتفقت الدر اسة الحالية مع الدراسـات السـابقة. در اسـة المزروعي (2015) استخدم فيها المنهج التجريبي، بينمـا در اسـة كير كوريان (2013) استخدمت المنهج الوصفي، مثل الدراسة الحالية. ـ ـ تمت در اسة المزروعي (2015) على مستوى دولة الكويت، بحيث تمت در اسـة كير كوريان (2013) على مستوى الو لايات المتحدة الأمريكية، واختلفت الدر اسـة الحالية عن الدراسـات السـابقة بحيث تم تطبيقها على مستوى المملكة العربية السعودية وخاصة بمحافظة جدة.

3. 3نهيَّة الدِّراسة وإجراعاتها

يتناول هذا الفصل الإجر اءات المنهجية للار اسة، من حيث منهج الدر اسـة الذي استخدم، وتحديد مجتمعه و عينته، و أدو اته من حيث بناءها، و التأكد من صدقها وثباتها، و الإجر اءات المتبعة في تطبيقها، وأسـاليب المعالجة الإحصـائية التي استخدمت في تحليل البيانات، وهذه الإجر اءات على النحو التالي: 
تم في هذه الدر اسة استخدام المنهج الوصفي التحليلي، الذي يعبّر عن الحالة المدروسـة تعبيرًا كميًا وكيفًا، حيث يمكننا وصف وتثخيص موضوع البحث وتحليل بعض جو انبه، كمـا أشـار عبيدات وزملائه (2004)، بأنه عبارة عن أسلوب يعتمد در اسـة الو اقع أو الظاهرة كما نوجد في الو اقع، وتنهم بوصفها وصفاً دقيقاً، ويعبر عنها تعبيراً كيفياً أو كمياً.

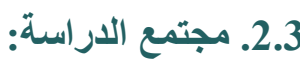

تكون مجتمع الدر اسـة من مجموعة أولياء أمور (أبـاء وأمهات) طلاب الصفوف العليا من المرحلة الابتدائية بمحافظة جدة، خلال العام الدر اسي 1441-1442هـ.

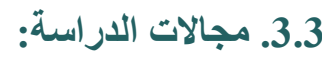

- المجال المكاني: يتمثل في مكتب التعليم بوسط جدة -

- المجال البشري: يتمثل في أولياء أمور طلاب الصفوف العليا من المرحلة الابتدائية (اباء و أمهات من سنة 9-12).

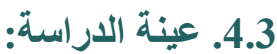

تم اخذ عينة عثو ائية من أولياء أمور طلاب الصفوف العليا من المرحلة الابتدائية بمحافظة جدة وقد بلغت عينة الدراسة (411) من أباء و أمهات حيث بلغ عدد الاباء (294) و الأمهات (117) الفصل الدراسي الثناني للعام 1441-1442هـ.

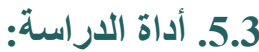

تم استخدام الاستبيان كأداة لهذه الدر اسة و الذي تم تصميمه من قبل الباحث بعد الاطلاع على العديد من الرسـائل و الكتب ذات الصلة بموضوع الدر اسة وفقاً للخطو ات التالية: خطوات إعداد أداة الاراسة وجمع البيانات:

بعد تحديد هدف الدر اسـة وهو قياس تأثنير استخدام الأجهزة الالكترونيـة على سلوك الأطفـال (من وجهة نظر الو الدين)، تم

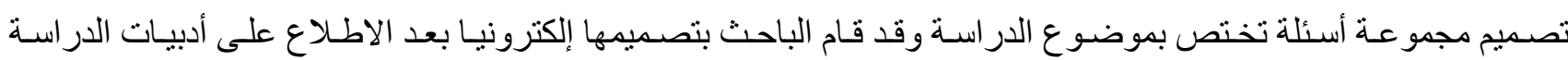
و الدر اسات السابقة، ومن ثم تم عرضـها على مجموعة من المختصين ذوي الخبرة في مجـال الدر اسـة وتم الاخذ بملاحظـاتهم و الخروج بالأداة في صورتها النهائية (ملحق 1) وتكونت من مجموعة من الأسئلة كما يلي:

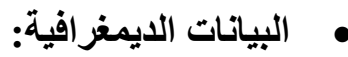

صفة ولي الأمر، العمر، الحالة الاجتماعية، عدد الأطفال، الحالة الاجتماعية، المستوى التعليمي، الدخل الثهري. أسئلة الدر اسة وتكونت من مجموعة من المحاور التالية: - المحور الأول: مدى تأثنير استخدام الأجهزة الالكترونية على التحصيل الدر اسي للأطفال - المحور الثاني: مدى تسبب استخدام الأجهزة الالكترونية في السلوك العدواني للأطفال 
- المحور الثالث: أثر المستوى التعليمي والاقتصادي للوالدين في توفير أجززة الكترونية لأطفالهم - - المحور الرابع: مدى تأثير الأجهزة الإلكترونية في الانطواء و الانعز ال الأسري - - المحور الخامس: مدى وجود اثار صحية على الأطفال باستخدام الأجهزة الالكترونية - المحور السادس: مدى تأثثر استخدام الأطفال للأجهزة الإلكترونية على قصور الانتباه وفرط الحركة

صدق الأداة:

المقصود بصدق الأداة: إلى أبي مدى تقبس الغرض الذي وضـعت من أجله، أو مدى تأثنير استخدام الأجهزة الإلكترونية على سلوك الأطفال، ولتحقيق ذلك تم تصميم الأداة بالرجوع إلى العديد من الدراسات و الدوريات التي تتاولت موضوع الدر اسة، حتى التى الوصول إلى الصورة النهائية لأداة الدر اسة. التأكد من صلاحية أدوات الدراسة: 1-معامل الثبات:

يقصد بثبات أداة القياس: أن تعطي النتائج نفسها إذا أعبد نطبيق الاستبانة على نفس العينة في نفس الظروف، وتم قياسه بالطرق

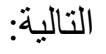
أ_معامل ثبات ألفاكرونباخ: تم حساب معامل ثبات ألفاكرونباخ باستخدام برنامج SPSS، وكانت النتائج: جدول (-3-3) معاملات الفاكرونباخ

\section{عدد العبارات الفاكرونباخ}

المحـاور

\begin{tabular}{|c|c|c|}
\hline 0.657 & 4 & مدى تأثثير استخدام الأجهزة الالكترونية على التحصيل الدر اسي للاطفال \\
\hline 0.687 & 4 & مدى تسبب استخدام الأجهزة الالكترونية في السلوك العدو اني للاطفال \\
\hline 0.735 & 4 & أثر المستوى التعليمي والاقتصادي للو الدين في توفير أجهزة الكترونية لأطفالهم \\
\hline 0.753 & 4 & مدى تأتثير الأجهزة الإلكترونية في الانطو اءو الانعز ال الأسري \\
\hline 0.685 & 4 & مدى وجود اثار صحية على الأطفال باستخدام الأجهزة الالكترونية \\
\hline 0.764 & 4 & مدى تأثير استخدام الأطفال للأجهزة الإلكترونية على قصور الانتباه وفرط الحركة \\
\hline 0.807 & 24 & الأداء ككل \\
\hline
\end{tabular}

\section{ب-صدق الاتساق الاخلي لفقرات الاستبانة:}

يقصد بالاتساق الداخلي لأسئلة الاستبانة: هي قوة الارتباط بين درجات كل مجال (عبار ات/محاور)، ودرجات أسئلة الاستبانة الكلية، والصدق ببساطة هو أن تقيس أسئلة الاستبانة أو الاختبار ما وضعت لقياسه، أي يقيس فعلا الوظيفة التي يفترض أن يقيسها، الجدول التالي يبين هذه المعاملات: 
المجلة الدولية لنشر البحوث والدراسات

جدول (2-3) معاملات الاتساق الداخلي لعبارات أداة الاراسة

\begin{tabular}{|c|c|c|c|}
\hline معامل الارتباط & رقم العبارة & معاهل الارتباط & رقم العبارة \\
\hline $.498(* *)$ & 13 & $.276(* *)$ & 1 \\
\hline $.480(* *)$ & 14 & $.257(* *)$ & 2 \\
\hline $.606(* *)$ & 15 & $.442(* *)$ & 3 \\
\hline $.548(* *)$ & 16 & $.173(* *)$ & 4 \\
\hline $.305(* *)$ & 17 & $.233(* *)$ & 5 \\
\hline $.487(* *)$ & 18 & $.441(* *)$ & 6 \\
\hline $.455(* *)$ & 19 & $.524(* *)$ & 7 \\
\hline $.476(* *)$ & 20 & $.465(* *)$ & 8 \\
\hline $.536(* *)$ & 21 & $.254(* *)$ & 9 \\
\hline $.415(* *)$ & 22 & $.267(* *)$ & 10 \\
\hline $.560(* *)$ & 23 & $.324(* *)$ & 11 \\
\hline $.534(* *)$ & 24 & $.371(* *)$ & 12 \\
\hline
\end{tabular}

وضّح الجدول التالي معيار الحكم على فقرات الاستبيان و الذي اعتمد مقياس ليكرت الخماسي (مو افق بثدة، موافق، محايد، غير مو افق، غير موافق بشدة).

جدول رقم (3-3) المدى وأوزان الإجابات والآراء السنائدة لها.

\begin{tabular}{|c|c|c|}
\hline الرأي السائد & الوزن & قيمة المتوسط \\
\hline غير مو افق بشدة & 1 & من 1 إلى أقل من 1.67 \\
\hline غير مو افق & 2 & من 1.67 إلى أقل من 2.6 \\
\hline محايد & 3 & من 2.6 إلى أقل من 3.4 \\
\hline مو افق & 4 & من 3.4 إلى أقل من 4.2 \\
\hline مو افق بشدة & 5 & من 4.2 إلى 5 \\
\hline
\end{tabular}

$$
\text { 6.3. إجراءات تطبيق الدراسة: }
$$

بعد تصميم أداة الدر اسة تم القيام بالإجر اءات التالية: تطبيق أداة الدراسة بتوزيعها إلكترونياً على أفراد الدر اسة. 
المجلة الدولية لنشر البحوث والدراسات

International Journal of Research and Studies Publishing

ISSN: 2709-7064
المجلد الثالث - الإصدار السابع والعشرون

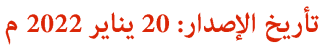

$$
\begin{aligned}
& \text { • تفريغ البيانات في برنامج (SPSS) لتحليلها إحصائياً. } \\
& \text { إيجاد الصدق والثبات لأداة الدر اسة. } \\
& \text { تحليل الأداة إحصائباً. } \\
& \text { 7.3. الأساليب الإحصائية المستخدمة: }
\end{aligned}
$$

تمت معالجة بيانات الدر اسة باستخدام الأساليب الإحصائية المناسبة لطبيعة هذه الدراسة، وذلك على النحو التالي: المتوسطات الحسابية والانحر افات المعيارية، لترتيب إجابات مفردات الدراسة لعبارات الاستبانة حسب درجة

$$
\text { المو افقة. }
$$

معامل ارتباط بيرسون (Pearson)، لإيجاد العلاقة بين بعض المتغيرات، وكذلك إيجاد معامل الاتساق الداخلي،

$$
\text { وتحديد نوع العلاقة بين المتغير ات و الدرجة الكلية للأداة، وكذللك للإجابة على الفرضيات. }
$$$$
\text { • • ععامل ألفاكرونباخ (ALPHA) لحساب ثبات محاور الدر اسة، و أداة الدراسة. }
$$

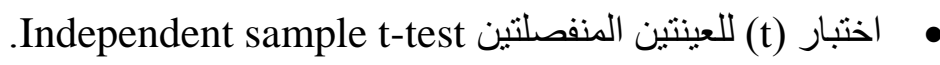

One Way ANOVA اختبار تحليل التباين الأحادي

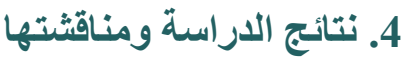

\section{تمهيد :}

هذا الفصل تناول تحليل نتائج الدر اسـة الميدانية (التحليل الإحصـائي) من خـلال عرض استجابات أفر اد عينـة الدر اسـة على

\begin{tabular}{|c|c|c|c|}
\hline النسبة & التكرار & توزيعات المثغير & المتغير ات الشخصية \\
\hline 71.5 & 294 & أب & \multirow{2}{*}{ صفة ولي الأمر } \\
\hline 28.5 & 117 & 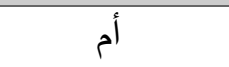 & \\
\hline 1.5 & 6 & 25 سنة فأقل & \multirow{4}{*}{ العمر } \\
\hline 5.6 & 23 & 30-26 سنة & \\
\hline 11.7 & 48 & 35-31 سنة & \\
\hline 23.6 & 97 & 40-36 سنة & \\
\hline
\end{tabular}
أسئلة الدر اسة الميدانية، ومعالجتها إحصائًا باستخدام مفاهيم الإحصاء الوصفي والاستدلالي و أساليبه الإحصائية، وصو لاً إلى لى

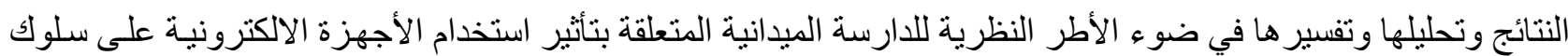
الأطفال، وكانت النتائج كما يلي: 1.4. التحليل الاحصائي للمتغيرات الشخصية:

جدول (1-4) توزيع أفراد العينة على حسب المتغيرات الثخصية. 
المجلة الدولية لنشر البحوث والدراسات

International Journal of Research and Studies Publishing

ISSN: 2709-7064
المجلد الثالث - الإصدار السابع والعشرون تأريخ الإصدار: 20 يناير 2022 م

\begin{tabular}{|c|c|c|c|}
\hline 57.7 & 237 & 41 سنة فأكثر & \\
\hline 95.6 & 393 & متزوج /-ة & \multirow{3}{*}{ الحالة الاجتماعية } \\
\hline 3.6 & 15 & مطلق/مة & \\
\hline .7 & 3 & أرمل/ـة & \\
\hline 51.1 & 210 & 3-3 أطفال & \multirow{4}{*}{ عدد الأطفال } \\
\hline 42.1 & 173 & 6-6 أطفال & \\
\hline 5.8 & 24 & 9-7 أطفال & \\
\hline 1.0 & 4 & 9 فأكثر & \\
\hline 73.0 & 300 & أعمل & \multirow{2}{*}{ الحالة المهنية } \\
\hline 27.0 & 111 & لا أعمل & \\
\hline 0 & 0 & أمي (لا يقر أو لا يكتب) & \multirow{6}{*}{ المستوى التعليمي } \\
\hline 1.2 & 5 & ابتدائي & \\
\hline 4.9 & 20 & متوسط & \\
\hline 20.4 & 84 & ثانوي & \\
\hline 56.2 & 231 & جامعي & \\
\hline 17.3 & 71 & در اسات عليا & \\
\hline 13.1 & 54 & لا يوجد دخل & \multirow{5}{*}{ الاخل الشهري } \\
\hline 4.6 & 19 & أقل من 3000 & \\
\hline 5.1 & 21 & $6000-4000$ & \\
\hline 11.9 & 49 & $9000-7000$ & \\
\hline 65.2 & 268 & 10000 فأكثر & \\
\hline
\end{tabular}


المجلة الدولية لنشر البحوث والدراسات

International Journal of Research and Studies Publishing

ISSN: 2709-7064
المجلد الثالث - الإصدار السابع والعشرون تأريخ الإصدار: 20 يناير 2022 م
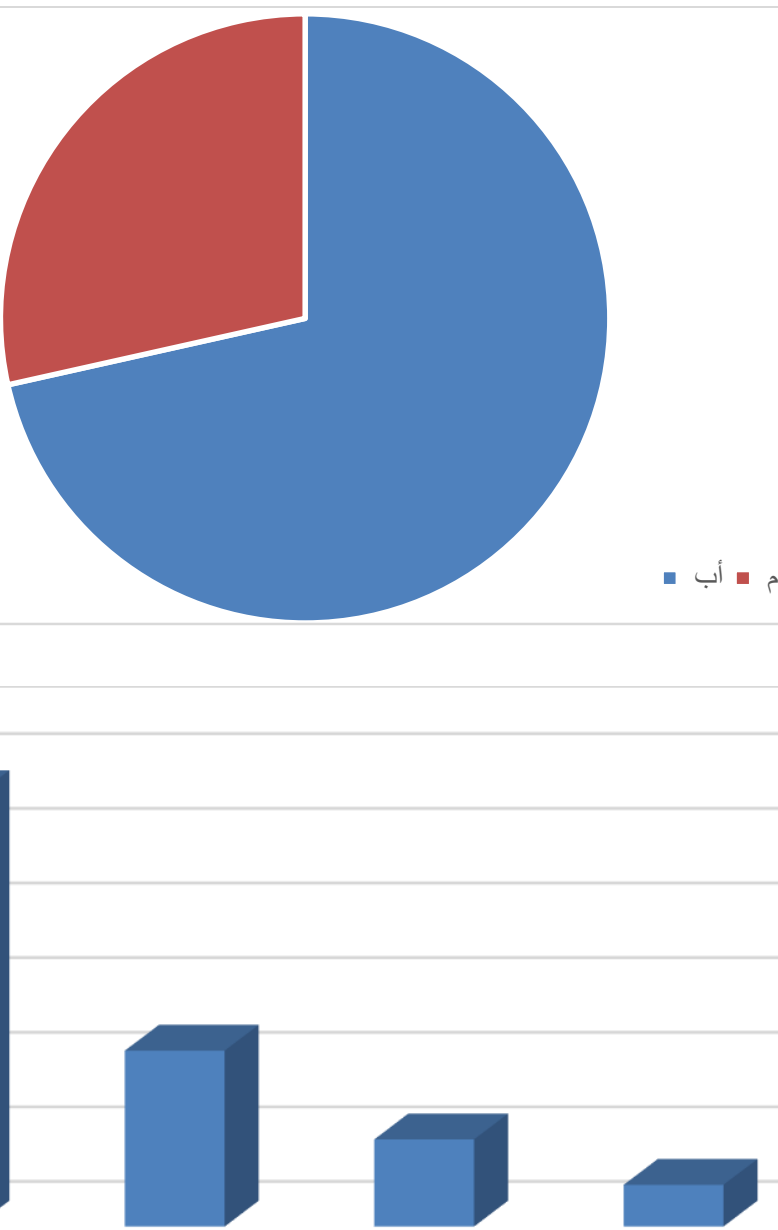

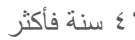

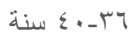

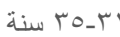

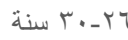

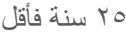

ويبين الجدول كذلك أن أغلب أفراد العينة حالاتهم الاجتماعية كانت (متزوج /_ة) بنسبة (95.6\%)، ومن ثم (مطلق/_ة) بنسبة (3.6\%)، وأخيراً (أرمل/_ة) بنسبة (0.7\%)، الثكل التالي يبين هذه النسب:

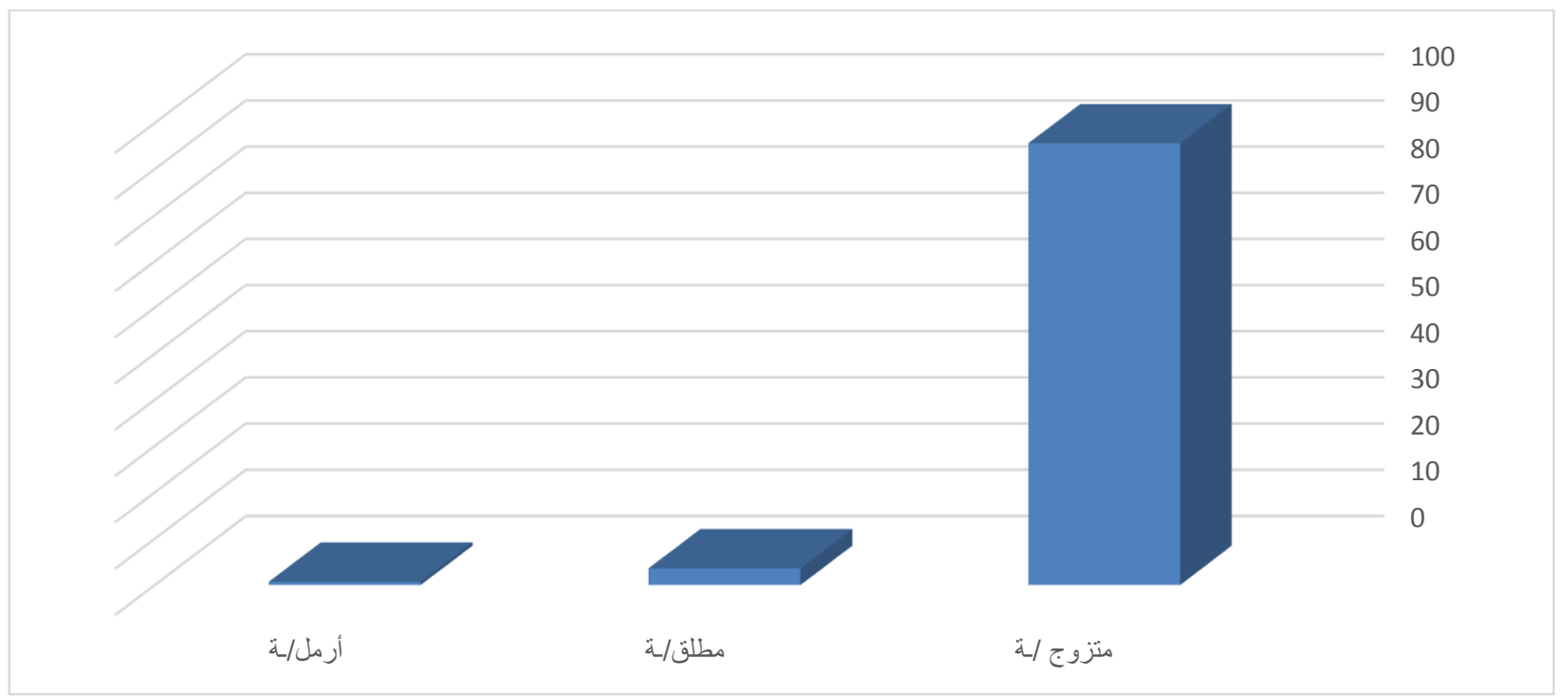


الجدول يبين أغلب أفراد العينة لديهم أطفال ما بين (1-3 أطفال) بنسبة (51.1\%)، ومن ثم عدد أطفال ما بين (4-6 أطفال) بنسبة (42.1\%)، تليها (7-9 أطفال) بنسبة (5.8\%)، و أخيراً (9 فأكثر) بنسبة (1\%)، الثكل التالي بيين هذه النسب:

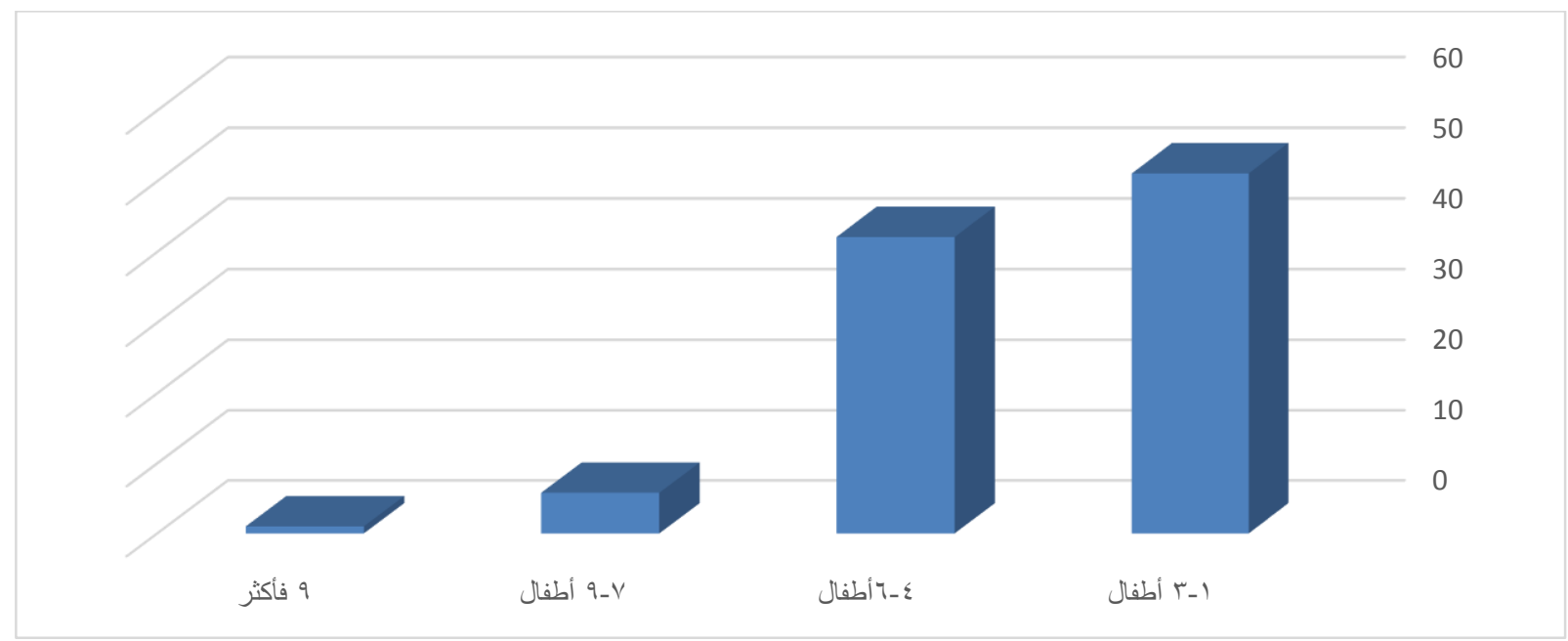

ووضحت نتائج الجدول كذلك أن أغلب أفر اد العينة حالاتهم المهنية يعملون بنسبة (73\%) بينما الذين لا عمل لهم بلغت نسبتهم (27\%)، الثكل التالي يبين هذه النسب:

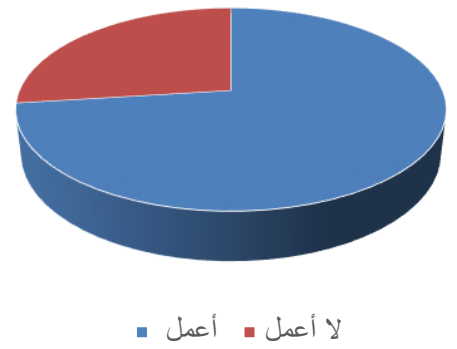

أوضحت النتائج أن أغلب أفراد العينة مستو اهم التعليمي جامعي بنسبة (56.2\%)، يليه الثانوي بنسبة (20.4\%)، ومن ثم الدر اسات العليا بنسبة (17.3\%)، ومن ثم المنوسط بنسبة (4.9\%)، و أخيراً الابتدائي بنسبة (1.2\%)، الثكل التالي يبين هذه

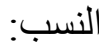




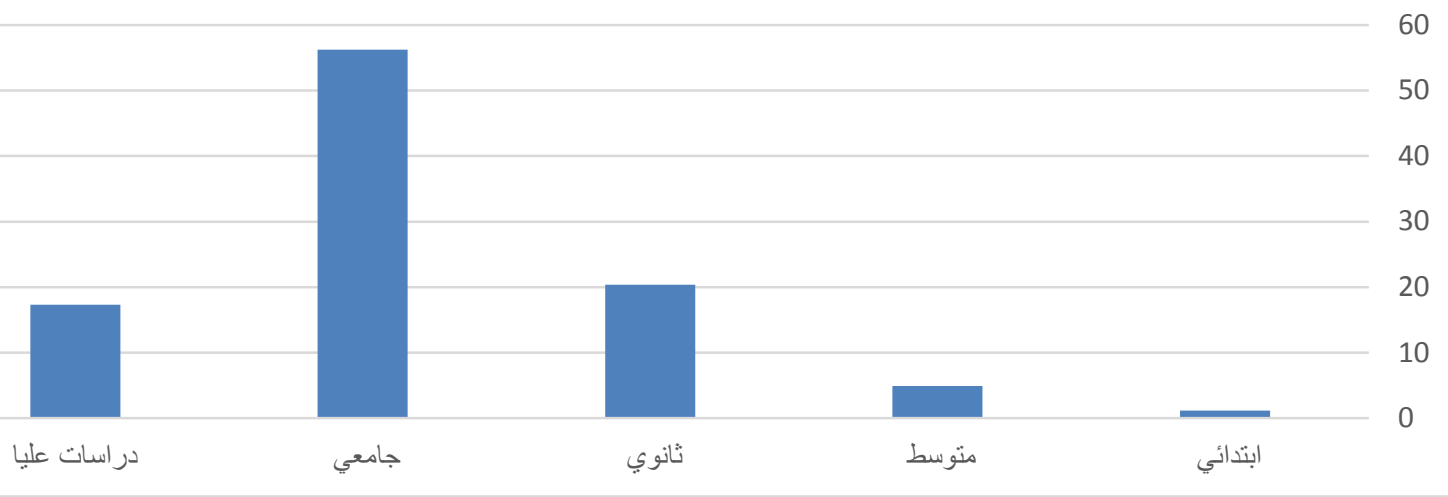

وكما بيين الجدول كذلك أن أغلب أفر اد العينة لديهم دخل شهري بلغ (10000 فأكثر) بنسبة (65.2\%)، ومن ثم لا يوجد لديهم دخل بنسبة (13.1\%)، تليها (7000 - 9000) بنسبة (11.9\%)، ومن ثم (4000 - 6000) بنسبة (5.1\%)، و أخيراً مستوى الدخل بنسبة (أقل من 3000) بنسبة (4.6\%)، الشكل التالي يبين هذه النسب:
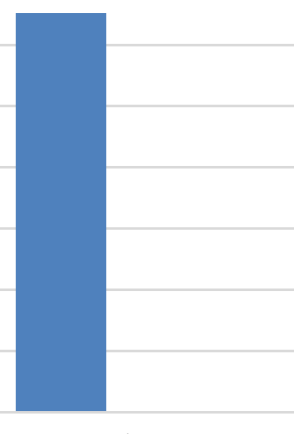

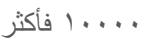

$q \ldots-v \ldots$
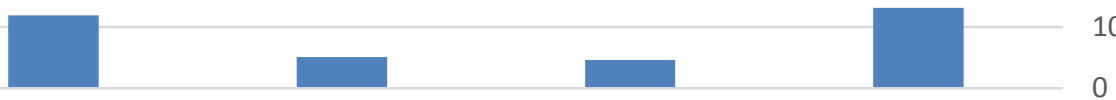

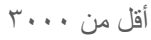

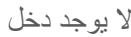

\section{4. التحليل الإحصائي لاستجابات عينة الدراسة على متغيرات الدراسة:}

في هذا الجزء تم عرض التحليل الإحصائي لاستجابات عينة الدر اسة لمتغيرات الدراسة، من خلال المحاور كما يلي: المحور الأول: مدى تأثثير استخدام الأجهزة الالكترونية على التحصبل الدراسي للأطفال جدول (4-2) المتوسطات الحسابية والانحرافات المعيارية والاوزان النسبية ودرجات الموافقة لإجابـات أفراد العينة على عبارات محور مدى تأثير استخدام الأجزة الاكترونية على التحصيل الاراسي للأطفال.

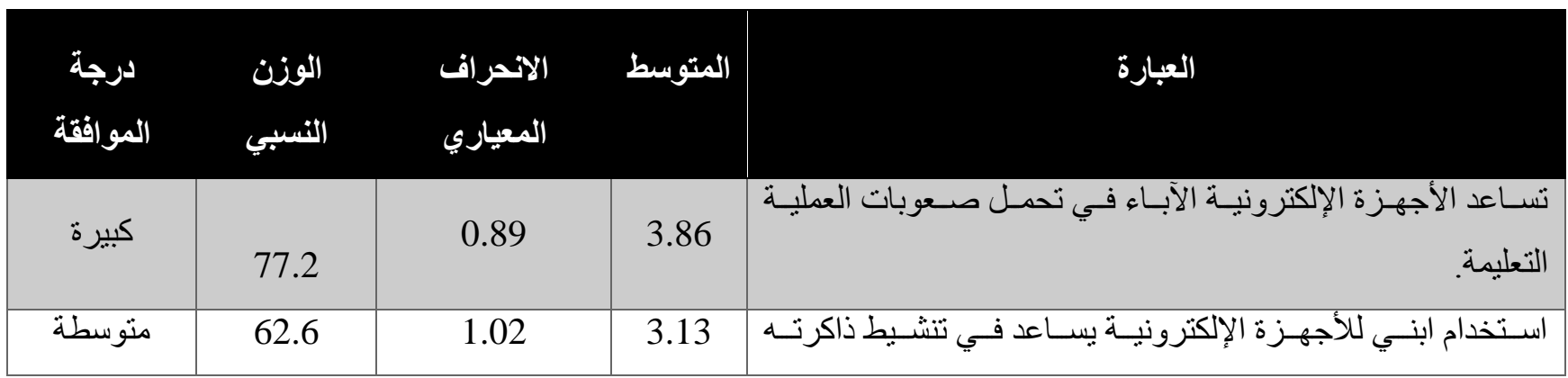


المجلة الدولية لنشر البحوث والدراسات

\begin{tabular}{|c|c|c|c|c|}
\hline & & & & التحصيلية. \\
\hline كبيرة جداً & 86 & 1.00 & 4.30 & دمافعية التعلم لديهة ابنـي للعب بـالأجهزة الإلكترونية لسـاعات طويلـة يقلل مـن \\
\hline متوسطة & 56.8 & 1.06 & 2.84 & الستخدام الأجهزة الإلكترونية لأبني سـاعد كثير أ في تحسن تحصبله \\
\hline كبيرة & 70.65 & 0.99 & 3.53 & \\
\hline
\end{tabular}

الجدول أعلاه عبارة عن المتوسطات الحسـابية والانحر افـات المعياريـة والأوزان النسبية ودرجـات الموافقة لعبـار ات الخاصـة محور مدى تأثثير استخدام الأجهزة الالكترونية على التحصيل الدر اسي للأطفال، فنجد أن المتوسط العام بلغ (3.53 من 5) يقع بداخل الفئة الر ابعة لمعيار ليكرت الخماسي (3.40 إلى 4.20) ممـا يعني أن أفر اد العينة مو افقين بدرجة كبيرة على مدى تأثثير استخدام الأجهزة الالكترونية على التحصيل الدر اسي للأطفال. المحور الثاني: مدى تسبب استخدام الأجهزة الاكترونية في السلوك العدواني للأطفال جدول (4-3) المتوسطات الحسابية والانحرافات المعيارية والاوزان النسبية ودرجات الموافقة لإجابـات أفراد العينة على عبار ات محور مدى تسبب استخدام الأجزة الاكترونية في السلوك العدواني للأطفال.

\begin{tabular}{|c|c|c|c|c|}
\hline درجة الموافقة & الوزن النسبي & المعياري & المتوسط & العبارة \\
\hline متوسطة & 60 & 1.17 & 3.00 & قضعزز حبـ الذات لأوقات طويلـة مـع الأجهزة الإلكترونيـة \\
\hline كبيرو جداً & 91.8 & 0.73 & 4.59 & الإدمان الإلكتروني. \\
\hline كبيرة جداً & 85.6 & 0.92 & 4.28 & حاد الثناء ممارسة ابني للعب بالأجهزة الإلكترونية يصبح \\
\hline كبيرة & 70 & 1.09 & 3.50 & الإلكترونية. لا يســـح ابنــي مطلقـاً للآخـرين باســتخدام اجهزتــهـ \\
\hline كبيرة & 76.85 & 0.98 & 3.84 & \\
\hline
\end{tabular}

الجدول أعلاه عبارة عن المتوسطات الحسابية والانحر افات المعيارية والأوزان النسبية ودرجات المو افقة لعبار ات محور مدى تسبب استخدام الأجهزة الالكترونية في السلوك العدو اني للأطفال، فنجد أن المنوسط العـام بلغ (3.50 من 5) يقع بداخل الفئة الر ابعـة لمعيـار ليكرت الخماسـي (3.4 إلى 4.2) ممـا يعني أن أفر اد العينـة مو افقين بدرجة كبيرة على مدى تسبب استخدام الأجهزة الالكترونية في السلوك العدواني للأطفال. 
المحور الثالث: أثر المستوى التعليمي والاقتصادي للوالدين في توفير أجهزة الكترونية لأطفالهم

جدول (4-4) المتوسطات الحسابية والاتحرافات المعيارية لتوزيع أفراد العينة على عبارات محور أثر المستوى التعليمي والاقتصادي للوالدين في توفير أجهزة الكترونية لأطفالهم لئية

\begin{tabular}{|c|c|c|c|c|}
\hline درجة الموافة & الوزن النسبي & 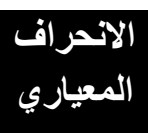 & المتوسط & العبارة \\
\hline متوسطة & 66.2 & 1.13 & 3.31 & واليومية لابني. الأجهـزة الإلكترونيـة ضــرورة فـي الحيـاة \\
\hline متوسطة & 60.2 & 1.12 & 3.01 & أجهزة الإلكترونية لأنبني. الدخل العـالي لأسرتي يحتم على توفير \\
\hline ضعيفة & 48.6 & 1.15 & 2.43 & 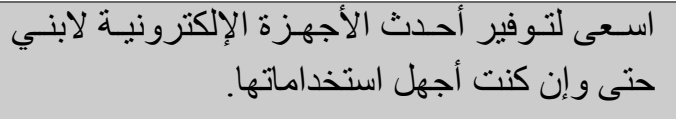 \\
\hline متوسطة & 67.6 & 1.16 & 3.38 & 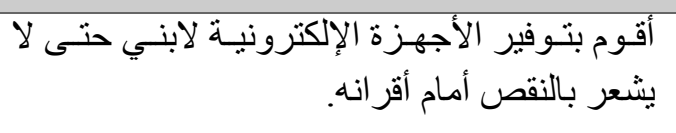 \\
\hline متوسطة & 60.65 & 1.14 & 3.03 & \\
\hline
\end{tabular}

الجدول أعلاه عبارة عن المتوسطات الحسابية و الانحر افات المعيارية والأوزان النسبية ودرجات الموافقة لعبار ات محور أثر المستوى التعليمي والاقتصادي للوالدين في توفير أجززة الكترونية لأطفالهم، فنجد أن المتوسط العام بلغ (3.03 من 5) يقع بداخل الفئة الثالثة لمعيار ليكرت الخماسي (2.60إلى 3.40) مدـا يعنـي أن أفر اد العينـة موافقين بدرجـة متوسطة على مدى تأثنير الحالة الاقتصادية لاقتناء الاسرة للأجهزة الالكترونية.

المحور الرابع: مدى تأثير الأجهزة الإكترونية في الانطواء والانعزال الأسري

جدول (4-5) المتوسطات الحسابية والانحرافات المعيارية لتوزيع أفراد العينة على عبارات محور مدى تأثير الأجهزة الإكترونية في الانطواء والانعزال الأسري.

\begin{tabular}{|c|c|c|c|c|}
\hline درجة الموافتة & الوزن النسي & 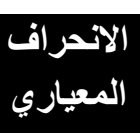 & المتوسط & العبارة \\
\hline كبيرة جداً & 86.2 & 0.85 & 4.31 & والمتخدام المحيط للأجهزة الإلكترونية يضعف التو اصل مـع الأسرة \\
\hline كبيرة جداً & 85.4 & 0.89 & 4.27 & يضعف أرى أن قضـاء ابنـي لســاعات طويلــة مـع الأجهـزة الإلكترونيـة \\
\hline كبيرة & 78.6 & 0.95 & 3.93 & 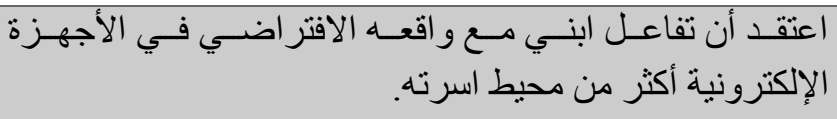 \\
\hline كبيرة & 71.8 & 1.26 & 3.59 & عائلية. \\
\hline كبيرة & 80.50 & 0.99 & 4.03 & \\
\hline
\end{tabular}


الجدول أعلاه عبارة عن المتوسطات الحسابية و الانحر افات المعيارية والأوزان النسبية ودرجات الموافقة لعبار ات محور مدى تأثير الأجهزة الإكترونية في الانطو اء والانعز ال الأسري، فنجد أن المتوسط العام بلغ (4.03 من 5) يقع بداخل الفئة الر ابعة لمعيار ليكرت الخماسي (3.40 إلى 4.20) مما يعني أن أفر اد العينة مو افقين بدرجة كبيرة على مدى تأثير الأجهزة الإلكترونية في الانطو اءو والانعز ال الأسري. ليكرب.

المحور الخامس: مدى وجود اثار صحية على الأطفال باستخدام الأجهزة الاكترونية

جدول (4-6) المتوسطات الحسابية والانحرافات المعيارية لتوزيع أفراد العينة على عبارات محور مدى وجود اثار صحية سالبة على الأطفال باستخدام الأجززة الاكترونية.

\begin{tabular}{|c|c|c|c|c|}
\hline درجة الموافة & الوزن النسبي & 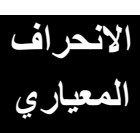 & المتوسط & العبارة \\
\hline منوسطة & 56.8 & 1.29 & 2.84 & 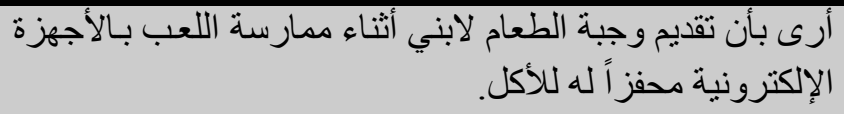 \\
\hline كبيرة جداً & 86.4 & 0.85 & 4.32 & جهازه العصبي. ممارسـة ابني للعب بـالأجهزة الإلكترونيـة يؤثر على \\
\hline كبيرة جداً & 84.4 & 0.95 & 4.22 & 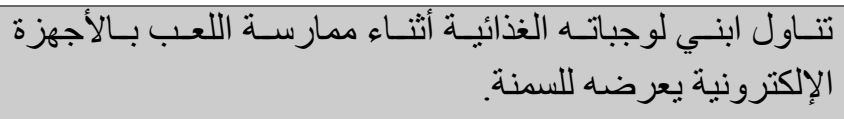 \\
\hline كبيرة & 77.2 & 1.07 & 3.86 & 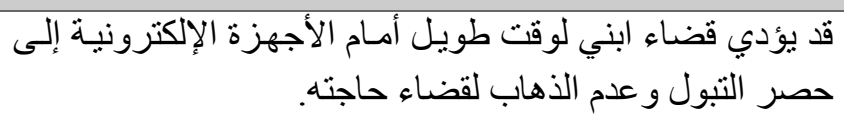 \\
\hline كبيرة & 76.20 & 1.04 & 3.81 & \\
\hline
\end{tabular}

الجدول أعلاه عبارة عن المتوسطات الحسابية والانحر افات المعيارية والأوزان النسبية ودرجات الموافقة لعبار ات محور وجود اثار صحية سالبة على الأطفال باستخدام الأجهزة الالكترونية، فنجد أن المتوسط العام بلغ (3.81 من 5) يقع بداخل الفئة الر ابعة لمعيار ليكرت الخماسي (3.40 إلى 4.20) مما يعني أن أفراد العينة مو افقين بدرجة كبيرة على مدى وجود اثار صحية سالبة على الأطفال باستخدام الأجهزة الالكترونية.

المحور السادس: مدى تأثير استخدام الأطفال للأجهزة الإكترونية على قصور الانتباه وفرط الحركة. جدول (4-7) المتوسطات الحسابية والاتحرافات المعيارية لتوزيع أفراد العينة على عبارات محور مدى تأثير استخدام الأطفال للأجزةة الإكترونية على قصور الاتتباه وفرط الحركة.

\begin{tabular}{|c|c|c|c|c|}
\hline درجة الموافة & الوزن النسبي & الانحراف & المتوسط & 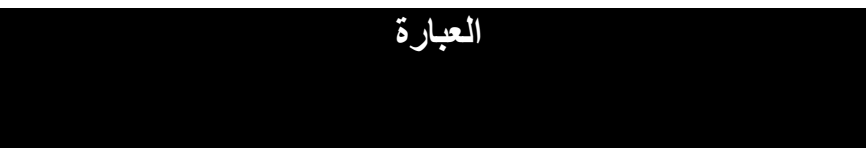 \\
\hline كبيرة & 80 & 1.04 & 4.00 & بشكل جيد. ابني فوضوي عند استخدامه للأجهزة الإلكترونية و لا يدير وقتـه \\
\hline كبيرة & 83.2 & 0.91 & 4.16 & لا يشعر ابني بالملل عن استخدامه للأجهزة الإلكترونية. \\
\hline
\end{tabular}




\begin{tabular}{|c|c|c|c|c|}
\hline كبيرة & 70.2 & 1.16 & 3.51 & 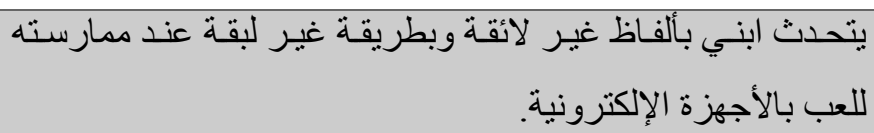 \\
\hline كبيرة & 70.4 & 1.18 & 3.52 & الإلكترونية. يستجيب ابني لتعليمـات وأوامر و الديـه عند استخدامه للأجهزة \\
\hline كبيرة & 75.95 & 1.07 & 3.80 & \\
\hline
\end{tabular}

الجدول أعلاه عبارة عن المتوسطات الحسابية والانحر افات المعيارية والأوزان النسبية ودرجات المو افقة لعبار ات محور مدى تأثير استخدام الأطفال للأجهزة الإلكترونية على قصور الانتباه وفرط الحركة، فنجد أن المتوسط العام بلغ (3.80 من 5) يقع بداخل الفئة الر ابعة لمعيار ليكرت الخماسي (3.40 إلى 4.20) مما يعني أن أفر اد العينة مو افقين بدرجة كبيرة على مدى تأثير استخدام الأطفال للأجهزة الإلكترونية على قصور الانتباه وفرط الحركة.

\begin{tabular}{|c|c|c|c|c|c|c|c|c|c|c|c|c|}
\hline \multicolumn{2}{|c|}{ السادس } & \multicolumn{2}{|c|}{ الخامس } & \multicolumn{2}{|c|}{ الر ابع } & \multicolumn{2}{|c|}{ الثالث } & \multicolumn{2}{|c|}{ اللاني } & \multicolumn{2}{|c|}{ الأول } & \multirow[t]{2}{*}{ المتغير ات } \\
\hline مستوى الدلاية & $\mathbf{T}$ & مستوى الدلالة & $\mathbf{T}$ & مستوى الدلالة & $\mathbf{T}$ & مستوى الدلالة & $\mathbf{T}$ & مستوى الدلالة & $\mathbf{T}$ & مستوى الالالة & $\mathbf{T}$ & \\
\hline .217 & 1.237 & .266 & 1.113 & .328 & .979 & .000 & 3.652 & .644 & .462 & .093 & 1.686 & صفه ولي \\
\hline مستوى الدلاكة & $\mathbf{F}$ & مستوى الدلالة & $\mathbf{F}$ & الدلالة & $\mathbf{F}$ & مستوى الدلالة & $\mathbf{F}$ & مستوى الدلاية & $\mathbf{F}$ & مستوى الدلالة & $\mathbf{F}$ & \\
\hline .282 & 1.268 & .263 & 1.316 & .020 & 2.963 & .012 & 3.261 & .326 & 1.164 & .036 & 2.600 & العمر \\
\hline مستوى الدلالة & $\mathbf{F}$ & مستوى الدلالة & $\mathbf{F}$ & مستوى الدلالة & $\mathbf{F}$ & مستوى الدلالة & $\mathbf{F}$ & مستوى الدلالة & $\mathbf{F}$ & مستوى الدلالة & $\mathbf{F}$ & \\
\hline .069 & 2.690 & .160 & 1.843 & .643 & .442 & .224 & 1.503 & .495 & .705 & 641 & .445 & الاجتماعية \\
\hline مستوى الدلالة & $\mathbf{F}$ & مستوى الدلاكة & $\mathbf{F}$ & الدلالة & $\mathbf{F}$ & الدلالة & $\mathbf{F}$ & مستوى الدلالة & $\mathbf{F}$ & مستوى الدلالة & $\mathbf{F}$ & \\
\hline .372 & 1.045 & .857 & .256 & .085 & 2.220 & .155 & 1.758 & .856 & .257 & .617 & .597 & عداد \\
\hline مستوى الدلاكة & $\mathbf{T}$ & مستوى الدلالة & $\mathbf{T}$ & مستوى الدلالة & $\mathbf{T}$ & مستوى الدلاكة & $\mathbf{T}$ & مستوى الدلالة & $\mathbf{T}$ & مستوى الدلالة & $\mathbf{T}$ & \\
\hline .470 & .724 & .457. & .744 & .573 & -.564 & .311 & 1.013 & .694 & -.394 & .612 & -.508 & المهنية \\
\hline مستوى الدلاكة & $\mathbf{F}$ & مستوى الدلالة & $\mathbf{F}$ & مستوى الدلالة & $\mathbf{F}$ & مستوى الدلالة & $\mathbf{F}$ & مستوى الدلالة & $\mathbf{F}$ & مستوى الدلالة & $\mathbf{F}$ & \\
\hline
\end{tabular}




\begin{tabular}{|c|c|c|c|c|c|c|c|c|c|c|c|c|}
\hline .413 & .990 & .018 & 3.014 & .781 & .439 & .169 & 1.619 & .169 & 1.618 & .776 & .446 & التعليمي \\
\hline مستوى الدلالة & $\mathbf{F}$ & مستوى الدلالة & $\mathbf{F}$ & مستوى الدلاكة & $\mathbf{F}$ & مستوى الدلالة & $\mathbf{F}$ & مستوى الدلالة & $\mathbf{F}$ & مستوى الدلالة & $\mathbf{F}$ & \\
\hline .176 & 1.589 & .023 & 2.871 & .322 & 1.173 & .464 & .900 & .273 & 1.291 & .771 & .451 & الثهري الاخل \\
\hline
\end{tabular}

وبنـاء على المتوسطات الحسـابية والانحر افـات المعياريـة تم ترتيب العبار ات تنازليـاً إبتداءً من العبـارة ذات المتوسط الأكبر و انتهاء بالعبارة ذات المتوسط الأصغر حيث نجد أن العبارة(لا يشعر ابني بالملل عن استخدامه للأجهزة الإلكترونية) في بدايـة الترتيب بمتوسط بلغ (4.16) ودرجة مو افقة كبيرة، ومن ثم العبارة (ابني فوضوي عند استخدامه للأجهزة الإلكترونية و لا يدير وقته بشكل جيـ) بمتوسط بلـغ (4.00) ودرجـة موافقة كبيرة، تليهـا العبـارة (لا يستجيب ابني لتعليمـات و أو امر و الديـه عند استخدامه للأجهزة الإلكترونيـة) بمتوسط بلـغ (3.52) ودرجـة مو افقة كبيرة، وأخير اً العبارة (يتحدث ابني بألفاظ غير لائقة وبطريقة غير لبقة عند ممارسته للعب بالأجهزة الإكترونية) بمتوسط بلغ (3.51) ودرجة مو افقة كبيرة.

\section{4. الفروق بين المتغيرات الشخصية في محاور أداة الدراسة:}

الغرض من هذا الاختبار معرفة مدى تأثير المتفيرات الثخصية في الإجابة عن أداة الدراسة وذلك لأن بعض المتغيرات

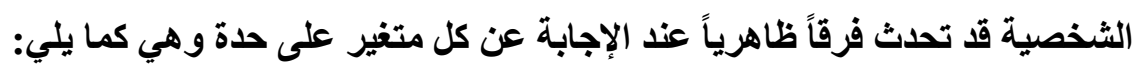
بينت نتائج الجدول أعلاه أن أنه لا نوجد فروق ذات دلالة إحصائية بين منوسطي متغير (صفة ولي الأمر) في محاور أداة الدراسة وذلك من خلال قيمة مستوى الدلالة الاحصائي لاختبار (T) المقابلة لكل محور حيث نجدها بلغت مستوى أكبر من (0.05) ما يعني أن متغير صفة ولي الأمر (أب / أم) لا يؤثر على اختبار ات محاور أداة الدراسة (أي تتقارب الاستجابات بحيث لا يوجد فرق بينها).

بينت نتائج الجدول أعلاه أنه لا توجد فروق ذات دلالة إحصائية بين منوسطات متغير (الحالة الاجتماعية) في محاور أداة الدر اسة وذلك من خلال قيمة مستوى الدلالة الاحصائي لاختبار (F) المقابلة لكل محور حيث نجدها بلغت مستوى أكبر من (0.05) ما يعني أن متغير الحالات الاجتماعية لا يؤثر على اختيار ات محاور أداة الدراسة (أي تثقارب الاستجابات بحيث لا

يوجد فرق بينها).

\section{4. ترتيب المحاور بناء على المتوسطات الحسابية:}

جدول (8-4) ترتيب المحاور وفقاً للمتوسطات الحسابية

\begin{tabular}{|c|c|c|c|c|}
\hline 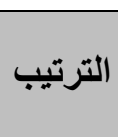 & النسبن & الانحراف المعياري & 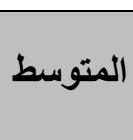 & 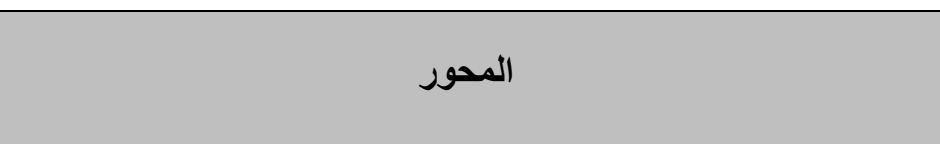 \\
\hline 5 & 67 & 1.03 & 3.35 & مدى تأثثير استخدام الأجهزة الالكترونية على التحصيل الدر اسي للأطفال \\
\hline 2 & 76.85 & 0.98 & 3.84 & مدى تسبب استخدام الأجهزة الالكترونية في السلوك العدو اني للأطفال \\
\hline
\end{tabular}




\begin{tabular}{|c|c|c|c|c|}
\hline 6 & 60.65 & 1.14 & 3.03 & ألطفالهم المستوى التعليمي والاقتصـادي للو الدين في توفير أجهزة الكترونية \\
\hline 1 & 80.5 & 0.99 & 4.03 & مدى تأثتير الأجهزة الإلكترونية في الانطو اءو الانعز ال الأسري \\
\hline 3 & 76.2 & 1.04 & 3.81 & مدى وجود اثار صحية على الأطفال باستخدام الأجهزة الالكترونية \\
\hline 4 & 75.95 & 1.07 & 3.38 & وفرط الحركة تـأثير استخدام الأطفـال للأجهزة الإلكترونيـة على قصـور الانتبـاه \\
\hline & 72.86 & 1.04 & 3.64 & 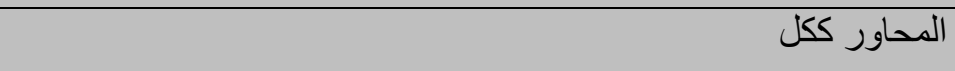 \\
\hline
\end{tabular}

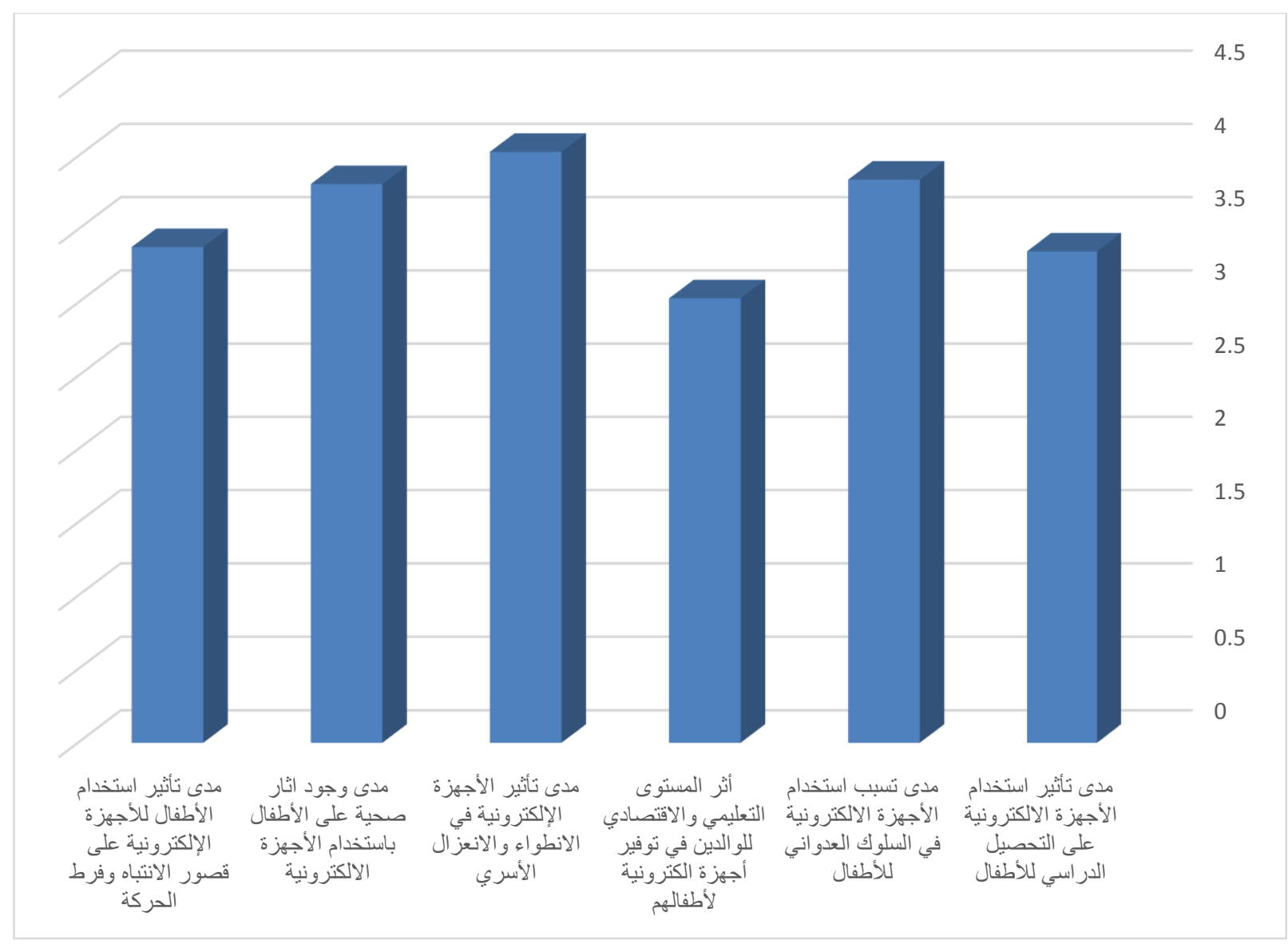

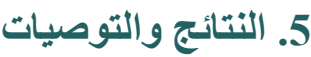

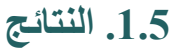

نتائج المتغيرات الثخصية:

أظهرت النتائج أن غالب أفر اد العينة بصفة أب بنسبة بلغت (71.5\%)، و أعمار هم في غالبها بداخل الفئة (41 سنة فأكثر ) بنسـبة (57.7\%)، وبحـالات اجتماعيـة متزوجين بنسـبة (95.6\%)، وغـالبهم بعدد أطفـال (1-3 أطفـال) بنسـبة (51.1\%)، 
وحالاتهم المهنية (أعمل) بنسبة (73\%)، بمسنوى تعليمي في الغالب جامعي بنسبة (56.2\%)، و غالبيتهم بمستوى دخل بلغ (10000) فأكثر ) بنسبة (65.2\%). نتائج المحاور:

أوضـت النتائج أن أفراد العينـة مـو افقين بدرجـة كبيرة على مدى تـأثنير استخدام الأجهزة الالكترونيـة على التحصيل الدر اسي للأطفال، وتتمثل في أهم العناصر التالية:

\section{تساعد الأجهزة الإلكترونية الآباء في تحمل صعوبات العملية التعليمة} ممارسة ابني للعب بالأجهزة الإلكترونية لساعات طويلة يقلل من دافعية التعلم لديه.

أفر اد العينة مو افقين بدرجة كبيرة على مدى تسبب استخدام الأجهزة الالكترونية في السلوك العدو اني للأطفال وتتمثل في

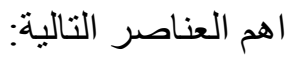

$$
\begin{aligned}
& \text { • ممارسة ابني للعب بالأجهزة الإلكترونية يؤدي إلى الإدمان الإلكتروني. } \\
& \text { أثناء ممارسة ابني للعب بالأجهزة الإلكترونية يصبح حاد المزاج. }
\end{aligned}
$$

أوضحت النتائج أن موافقين بدرجة متوسطة على أثر المستوى التعليمي والاقتصادي للوالدين في نوفير أجهزة الكترونية لأطفالهم، وتتمثل في أهم العناصر التالية:

$$
\text { وجود الأجهزة الإلكترونية ضرورة في الحياة اليومية لابني }
$$

• أقوم بتوفير الأجهزة الإلكترونية لابني حتى لا يشعر بالنقص أمام أقر انه.

بينت النتائج أن أفر اد العينة مو افقين بدرجة كبيرة على مدى تأثير الأجهزة الإلكترونية في الانطواءو الانعزال الأسري، وتتمثل في أهم العناصر التالية:

$$
\text { • استخدام ابني للأجهزة الإلكترونية يضعف التو اصل مع الأسرة و المجتمع المحيط }
$$
• أرى أن قضاء ابني لساعات طويلة مع الأجهزة الإلكترونية يضعف الحوار و التعبير لديه.

أوضحت أن أفر اد العينة مو افقين بدرجة كبيرة على مدى وجود اثار صحية على الأطفال باستخدام الأجهزة الالكترونيـة، وتتمثل في أهم العناصر التالية:

$$
\text { • اعتقد بأن ممارسة ابني للعب بالأجهزة الإلكترونية يؤثر على جهازه العصبي }
$$

تناول ابني لوجباته الغذائية أثناء ممارسة اللعب بالأجهزة الإلكترونية يعرضه للسمنة.

أوضـحت النتائج أن أفر اد العينة مو افقين بدرجة كبيرة على مدى تأثثير استخدام الأطفال للأجهزة الإلكترونيـة على قصور الانتباه وفرط الحركة، وتتمثل في أهم العناصر التالية: 


$$
\begin{aligned}
& \text { ابني فوضوي عند استخدامه للأجهزة الإلكترونية و لا يدير وقته بشكل جيد. } \\
& \text { لا يثعر ابني بالملل عن استخدامه للأجهزة الإلكترونية. }
\end{aligned}
$$

هنـاك فروقـاً ذات دلالـة إحصـائية بـين منوسـات أعمـار أفر اد العينـة في المحساور (مدى تـأثير استخدام الأجهزة الالكترونية على التحصيل الدراسي للأطفال، أثر المستوى التعليمي و الاقتصادي للوالدين في توفير أجهزة الكترونيـة لأطفالهم، مدى تأثثير الأجهزة الإلكترونية في الانطو اءو والانعز ال الأسري) عند مستوى دلالة احصائي (0.05). توجد فروق ذات دلالة إحصائية بين متوسطات المستويات التعليمية في محور (مدى وجود اثار صحية على الأطفال

$$
\text { باستخدام الأجهزة الالكترونية) عند مستوى دلالة احصائي (0.05). }
$$

مشاركة الاطفال في وضع قو اعد خاصة حول الاستخدام السليم و الآمن للجهاز مثل تحديد الوقت و المكان و المدة

$$
\text { المسموح بها. }
$$

مسـاعد الاطفـال على تعلم كيفيـة الحفـاظ على خصوصية المعلومـات الثخصيبة خاصسةً مـن الغربـاء، فبعض

$$
\text { الأشخاص ليسوا كما يدعون. }
$$

تذكير الأطفال بأن ما يحدث عبر الإنترنت يبقى على الإنترنت ومن الصـب حذفه الرسـئل و الصـور ومقاطع

$$
\text { الفيديو. }
$$

تعليم الاطفال أن يحترموا دائمًا المعلومات الثخصية للأصدقاء والعائلة و ألا يشاركو ا بأي معلومات مع الآخرين

$$
\text { قد تسبب لهم إحر اج أو أذى. }
$$

تعويد الاطفال في سن الدراسة الاستخدام الايجابي للأنترنت في التواصل السليم وحل الواجبات و التو اصل مـع

$$
\text { معلميهم. }
$$

• عدم ترك الاطفال يعبثون بأجهزة الآخرين أو محاو لاتهم للوصول لمعلومات خاصة بهر.

• عدم ترك الاطفال يتناولون طعامهم أثناء ممارساتهم الالعاب الالكترونية عبر الاجهزة.

\section{6. - قائمة المراجع والمصادر}

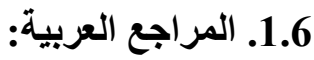

ـ الصباح، سليم (2015) التحديات و التغيرات التي يعانون منها الولدين مع أبنائهم الذين هم في سن مبكرة، الكويت:

$$
\text { الجامعة الكوينية، كلية التربية. }
$$

ـ المزروعي، خليفة (2015) استر اتيجية توظيف الجاهزة الذكية في مجال تعليم الطفل، الكويت، جامعـة الكويت، كليـة

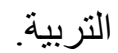


- الرملي، حسين (2016) التحديات التي نواجه الآباء مع أبنائهم عند استخدام الأجززة الذكية، رسالة ماجستير مقدمة للجامعة الأردنية بعمان.

- المصري، أحمد حسين بكر(2018) تطبيقات الأجهزة الذكية لإدارة المكتبـات ومصـادر المعلومـات الثخصية: دراسـة

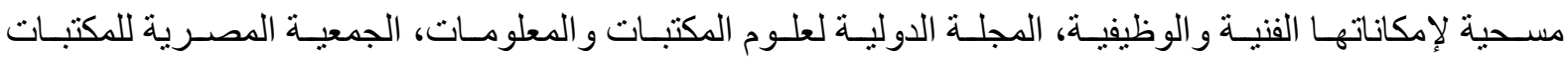
و المعلومات و الأرشيف

ـ ـ الحربي، مشعل حسن حميد (2016) الأجززة الذكية وآثار ها الاجتماعية من وجهة نظر طلاب المرحلة الثانوية. مجلة القر اعة و المعرفة_مصر العقيل منيره خالد، (2013)" بعض الآثار السلبية لوسـائل التقنية الحديثة على سلوك الأطفال، رسـالة دكتور اه غير منشورة جامعة الإمام محمد بن سعود الإسلامية، الرياض. ــ الرمـادي أمـاني زكريـا، (2008)" المكتبـات العربيـة و آفـاق تكنولوجيـا المعلومـات، مركـز الإسـكندرية للكتـاب، الإسكندرية.

- القومي محمد عبد الفضيل، (1984)" قر اعة اسلامية في علم النفس العام، دار الطباعة المحمدية"، القاهرة. - الفسفوسي، عدنان احمد، (2011)" المرجع البسيط في اساليب تعديل السلوك". ــ العظامات، خديجه، (2018)" التأثير السلبي لوسيائل تكنولوجيـا الاتصـال الحديثة على تربيـة النشء"، مجلـة جامعـة النجاح للأبحاث، فلسطين. - - الهدلق، عبد الله عبد العزيز، (2013)" إيجابيـات وسلبيات الألعـاب الإلكترونيـة ودو افع ممارسنها من وجهة نظر طلاب التعليم العام بمدينة الرياض، مجلة القر اهة، مصر. الصقعبي، مشـاعل محد، (2015)"التحديات التي تفرضها الأجهزة الإلكترونية على الحوار و التو اصل مـع الطفل"، المجلة التربوية الدولية المتخصصة، الرباط ـ العبودي، سـتار جـابر غـانم، (2008)" القلق لدى الأطفـال مـن مستخدمي الألعـاب الإلكترونيـة، مجلـة كليـة الآداب، جامعة بغداد. - ـ الحربي، عبد الكريم؛ و الجبر، جبر (2016). وعي معلمي العلوم بالمرحلة الابتدائية في محافظة الرس بمهار ات المتعلمين للقرن الحادي و العشرين ـالمجلة التربوية الدولية المتخصصة. - العجمي، محمد عبد السلام و آخرون، (2014)" تربية الطفل في الإسلام النظرية والتطبيق"، دار الرشد، الرياض. - إسماعيل، عفاف عبد الله، عبد الرحمن، عبد الرحمن جعفر (2009) تأثثير الإنترنت على علاقات الثباب الاجتماعية و الأسـرية. در اسـة ميدانيـة على عينـة مـن شباب مدينـة الخرطوم-السـودان، المؤتثر العلمـي الأول الأسـرة والإعـلام وتحديات العصر، القاهرة - بركات، وجدي محمد وتوفيق عبد المنعم، الأطفال و العولمة الافتر اضية آمال و أخطار ، مؤنم الطفولة في عالم متغير ، البحرين باسم، أسماء عبد الرحمن، إيمان (2018)" التأثيرات السلبية لاستخدام الهواتف الذكية على الأطفال من وجهة نظر الأمهات غزة" جامعة النجاح الوطنية كلية الإعلام قسم الصحافة المكتوبة والإلكترونية. 
- Hysing, M., Pallesen, S., Stormark, K. M., Jakobsen, R., Lundervold, A. J., \& Sivertsen, B. (2015). Sleep and use of electronic devices in adolescence: results from a large populationbased study. BMJ open, 5(1), e006748

- Sundus, M. (2018). The impact of using gadgets on children. Journal of Depression and Anxiety, 7(1), 1-3

- Cain, N., \& Gradisar, M. (2010). Electronic media use and sleep in school-aged children and adolescents: A review. Sleep medicine, 11(8), 735-742.

- Subrahmanyam, K., Greenfield, P., Kraut, R., \& Gross, E. (2001). The impact of computer use on children's and adolescents' development. Journal of Applied Developmental Psychology, 22(1), 7-30

- Smahel, D., Wright, M. F., \& Cernikova, M. (2015). The impact of digital media on health: children's perspectives. International journal of public health, 60(2), 131-13

Doi: $\underline{\text { doi.org/10.52133/ijrsp.v3.27.12 }}$ 